\title{
An Incentive-Based Approach to Regulating Workplace Chemicals
}

\begin{abstract}
JASON R. BENT*
The United States' system for regulating employee exposures to hazardous chemicals is broken. Absent regulation, the labor market fails to produce efficient levels of precaution against chemical exposures. Information asymmetries, long disease latency periods, and other characteristics of chemical exposures thwart the market's ability to produce efficient risk wage tradeoffs. These same characteristics permit employers and chemical manufacturers to externalize the costs of illnesses caused by chemical exposures. The current U.S. regulatory system, including a combination of Occupational Safety and Health Administration (OSHA) regulations and state workers' compensation programs, is not correcting the labor market's failure. The result is a level of workplace chemical exposure risk that is systematically too high, and a level of precaution that is systematically too low.
\end{abstract}

The reforms proposed in the literature to date do not harness the financial incentives of the least-cost information providers and least-cost risk avoiders: chemical manufacturers and employers. This Article takes the search for a solution in a new direction by using state workers' compensation laws to capitalize on the incentives of chemical manufacturers and employers. The Article argues that state workers' compensation laws should be amended in two ways: (1) shift the default burden of proof on causation to the respondents, but only in cases where there is no applicable OSHA exposure limit, and (2) allow employers to include chemical manufacturers as respondents in workers' compensation proceedings for purposes of apportioning liability. These amendments could be implemented by convening a new National Commission on State Workers' Compensation Laws. The result would be a new push for OSHA chemical exposure limits by chemical manufacturers and employersthe entities in the best position to provide the toxicity and precaution information necessary to support OSHA regulations.

\section{TABLE OF CONTENTS}

I. INTRODUCTION

II. THE DiacETYL StORY

A. The Discovery of "Popcorn Lung"

* Assistant Professor of Law, Stetson University College of Law; J.D., University of Michigan Law School (2000). I am grateful for the helpful comments and suggestions on prior drafts of this paper offered by: Bradley A. Areheart, Shaina Bent, James W. Fox, Jr., Marco J. Jimenez, Melissa Luttrell, the Honorable Robert Moss, Michael D. Smith, Nathan Strup, and Michael J. Zimmer. A version of this paper was presented at the Sixth Annual Colloquium on Current Scholarship in Labor and Employment Law on September 16-17, 2011. Thank you to the faculty and administration of the Stetson University College of Law and the Pennsylvania State University Dickinson School of Law for providing generous research support. Finally, thank you to Tayler Summers and Lindsay Houser for providing exemplary research assistance. 
B. Diacetyl and Recurring Themes in Chemical Exposure

Cases 1400

1. Innocent Until Proven Guilty.........................................1400

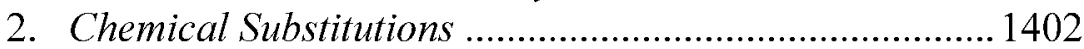

3. Assertion of Trade Secret Protection.............................. 1404

4. Unique Aspects of the Diacetyl Story .............................1405

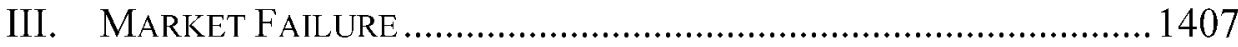

A. Information Failures Preclude Efficient Ex Ante Wage Differentials 1407

B. Negative Externalities Prevent the Efficient Imposition of Ex Post Compensation Costs on Employers

IV. Failure of the CuRRent Regulatory Regime. 1412

A. State Workers' Compensation Statutes: A Breakdown of the Implicit Social Bargain in Chemical Exposure Cases .... 1412

B. The Tort System Fails as an Alternative Source of Ex Post Compensation

C. OSHA Exposure Limits 1420

D. OSHA Information Communication Standards 1422

E. OSHA Voluntary Compliance and Cooperative Programs .. 1424

V. PRIOR PROPOSALS FOR REFORM 1426

A. The Superfund Model for Funding Independent Government Research 1427

B. Opt-Out OSHA Standards. 1429

C. Combining Social Insurance Programs and Risk-Based Taxes 1430

D. Public Nuisance Actions Requiring Testing 1432

E. Amending the OSH Act to Categorize Hazards and Shift Burdens for High-Risk Hazard Categories

F. The REACH Model

VI. Proposed Solution: GetTing EMPloyers and Chemical Manufacturers to Push For New Exposure Standards .... 1437

A. Proposal Goals and Features...

1. Proposal Feature 1: A Default Burden Allocation Framework

2. Proposal Feature 2: Expanding Worker Disease

Statutes to Cover Chemical Manufacturers...

B. Implementation: A New National Commission on State Workers' Compensation Laws and Recommended State Statutory Amendments 


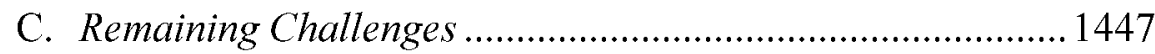

1. Solving the Trade Secret Problem ................................... 1447

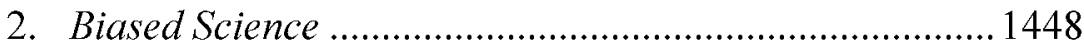

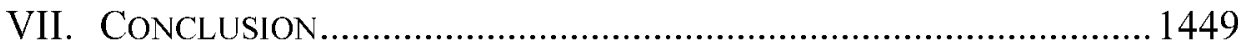

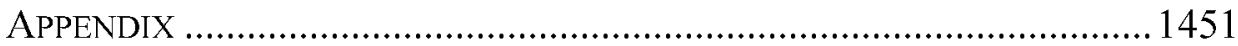

Table 1: New York Workers' Compensation Law ................... 1451

\section{INTRODUCTION}

The United States' system for regulating employee exposures to hazardous chemicals in the workplace is broken. Approximately 80,000 different chemicals are used in industrial commerce today, with nearly 1,000 new chemicals added to the market every year. ${ }^{1}$ Yet, even the most basic toxicity information is available for only a tiny fraction of those chemicals. ${ }^{2}$ Only about 500 chemicals are regulated by an Occupational Safety and Health Administration (OSHA) exposure limit. ${ }^{3}$ The rest are essentially unregulated as to employee exposures. The dearth of toxicity information and exposure regulation, combined with long disease latency periods, allow employers and chemical manufacturers to externalize much of the expected cost of occupational chemical exposures. The result is a level of employee exposure risk that is systematically too high and a level of precaution that is systematically too low. ${ }^{4}$ This Article advances a proposal to correct the market and regulatory failures by capitalizing on the fundamental financial incentives of employers and chemical manufacturers.

The workplace safety regime in the United States consists of three complementary components: (1) the labor market and its capacity to set compensating wage differentials for risky work before any injury has occurred

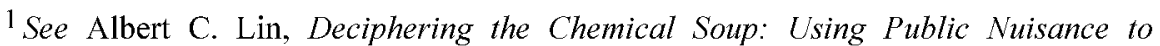
Compel Chemical Testing, 85 NOTRE DAME L. REV. 955, 95960 n.12 (2010) (citing U.S. Gov't Accountability Office, Chemical Regulation 1-2 (2005), available at http:/www.gao.gov/new.items/d05458.pdf (stating there are over 82,000 chemicals listed in EPA's Toxic Substances Control Act inventory)).

${ }^{2}$ See id.

${ }^{3}$ Sidney A. Shapiro \& Rena Steinzor, Capture, Accountability, and Regulatory Metrics, 86 TEX. L. REV. 1741, 1779 (2008); see also Is OHSA Working for Working People?: Hearing Before the Subcomm. on Employment and Workplace Safety of the S. Comm. on Health, Education, and Pensions, 110th Cong. 9 (2007) (statement of David Michaels, Ph.D., Research Director and Associate Chairman of the Department of Environmental and Occupational Health, George Washington University, Washington, D.C.) [hereinafter IS OSHA Working?], available at http:/www.gpo.gov/fdsys/pkg/CHRG-110 shrg35165/pdf/CHRG-1 10shrg35165.pdf.

${ }^{4}$ See W. Kip Viscusi, Structuring an Effective Occupational Disease Policy: Victim Compensation and Risk Regulation, 2 YALE J. ON REG. 53, 57-60 (1984). "These externalities lead workers and employers to undervalue the true social cost of occupational disease and thus to put too little emphasis on risk reduction and disease insurance." $I d$. at 60 . 
(ex ante compensation); (2) the workers' compensation system, which replaces tort suits against employers and provides limited compensation to workers after they are actually injured in the course of the work (ex post compensation); and (3) command and control health and safety regulations, including chemical and substance exposure regulatory limits set by OSHA and enforced through regulatory monitoring and penalties.

This three-pronged workplace safety regime has two primary goals: first, to prevent unreasonable (inefficient) risks of worker injuries or illnesses; second, to provide adequate compensation to those workers who suffer an injury or illness from working. 5 In theory, the three separate components of this workplace safety regime should work together to lead employers to take an optimal level of precaution-avoiding unreasonable risks-and also to adequately compensate injured employees. ${ }^{6}$

In an efficient labor market, the first component of the regime would allow workers inclined to accept riskier jobs to demand risk premiums and thereby obtain their preferred blend of wages and risk. ${ }^{7}$ The second component would impose ex post costs on risky employers through workers' compensation awards (or, for insured employers, increased workers' compensation insurance premiums). Employers would then, in theory, take precautions to avoid or reduce risk to the point at which the marginal cost of doing so exactly equals the marginal benefit to the employer in avoiding any additional wage premium and workers' compensation costs it would incur from additional risk-taking. ${ }^{8}$ In addition to setting efficient levels of risk and precaution, the combined effects of the first two components should theoretically operate to accurately compensate workers for their expected costs of injury from a particular job, thereby satisfying the second goal. The third component of the regime is pure regulatory intervention. OSHA uses its authority to establish certain minimum standards for workplace safety and punishes employers who violate those standards. ${ }^{9}$

How well these three components work together to prevent unreasonable risks of workplace accidents is open to debate. Looking only at the statistics for

5 See id. at 56-57.

${ }^{6}$ See id.

${ }^{7}$ See id.

${ }^{8} I d$. at 56.

${ }^{9}$ Thomas O. McGarity, Reforming OSHA: Some Thoughts for the Current Legislative Agenda, 31 Hous. L. REv. 99, 101 (1994). Economists often criticize the regulatory third component as unnecessary and inefficient, because it may prevent potential gains from trade where employees with preferences for risk might be willing to take on a level of risk above that set by the command and control regulations, in exchange for a sufficient wage premium, and the employer would likewise prefer to pay the wage premium plus any ex post costs from workers' compensation rather than implement expensive precautions mandated by the OSHA regulation. See, e.g., Thomas A. Lambert, Avoiding Regulatory Mismatch in the Workplace: An Informational Approach to Workplace Safety Regulation, 82 NEB. L. REV. 1006, 1010 (2004) (advocating a more limited regulatory scheme, which would generally replace command and control OSHA regulations with information disclosure regulations). 
on-the-job injuries and accidental fatalities in the workplace, it would appear that American workplaces are, in the aggregate, getting safer. ${ }^{10}$ But for workplace diseases, the regime is failing. The Department of Labor's Bureau of Labor Statistics (BLS) tracks the number of work-related illnesses reported by employers to OSHA, and those numbers reflect a decline in recent years. ${ }^{11}$ However, disease latency and persistent causation questions undermine the accuracy of the BLS statistics for occupational diseases. ${ }^{12}$ Illnesses caused by chronic exposure often do not manifest themselves until several years after exposure, sometimes long after employees have separated from the employer. ${ }^{13}$ This prevents accurate reporting to the BLS. ${ }^{14}$ Unlike on-the-job physical injuries, "[m] ost occupational illnesses that are caused" by toxic exposures are not captured by any tracking system. ${ }^{15}$

The problem is exacerbated by a persistent toxicity data gap for industrial chemicals. ${ }^{16}$ This toxicity data gap has been well-recognized by scholars in the environmental and employment law literature, and it impedes the ability to trace any particular disease to an identifiable workplace exposure to a given chemical. ${ }^{17}$ Current U.S. environmental and worker safety laws tend to

${ }^{10}$ Rate of Fatal Work Injuries per 100,000 Workers, 1992-2005, U.S. BUREAU OF LABOR STAT., http://www.bls.gov/iif/oshwc/cfoi/cfoi2005 02.pdf (last visited Nov. 7, 2012) (reflecting decline in workplace fatalities from 5.2 per $10 \overline{0}, 000$ full-time-equivalent workers in 1992 to 4.0 in 2005).

${ }^{11} \mathrm{Id}$.

12 Viscusi, supra note 4 , at 54.

${ }^{13} \mathrm{Id}$.

${ }^{14} I d$; RAY MARSHaLl, U.S. DEP'T OF LABOR, AN INTERIM REPORT TO CONGRESS ON OCCUPATIONAL DISEASE 12 (1980), available at http:/legacy.library.ucsf.edu/tid/fcs96d00/ pdf;jsessionid=56130CD88FF09D730A355FF2E0A88709.tobacco03 ("Finally, all known industrial carcinogens are associated with long-latency periods which obscure the association between workplace and disease.").

${ }^{15}$ Is OSHA Working?, supra note 3, at 7 (statement of David Michaels, Ph.D., Research Director and Associate Chairman of the Department of Environmental and Occupational Health, George Washington University, Washington, D.C.) ("Most occupational illnesses that are caused by toxic exposures are never recorded as work-related, either because they occurred after the worker left the employment where the exposure occurred or because the link with occupational exposure was never made.").

${ }^{16}$ John S. Applegate, Bridging the Data Gap: Balancing the Supply and Demand for Chemical Information, 86 TEX. L. REV. 1365, 1381 (2008) ("As this chart summarizing the Toxicity Testing results shows, there is a consistent data gap across all categories of industrial chemicals, regardless of production volume.").

${ }^{17} \mathrm{See}$, e.g., id. at 1380-81; Lin, supra note 1, at 961-62; Wendy Wagner, Using Competition-Based Regulation to Bridge the Toxics Data Gap, 83 IND. L.J. 629, 635-36 (2008); Wendy E. Wagner, Commons Ignorance: The Failure of Environmental Law to Produce Needed Information on Health and the Environment, 53 DukE L.J. 1619, 1631-33 (2004). Chemical manufacturers acknowledge the existence of this information gap. Lin, supra note 1, at 959-60 ("[E]ven the chemical industry has acknowledged the wide information gap. Hundreds of new chemicals enter the flow of commerce each year, exacerbating the situation." (footnote omitted)). 
perpetuate this data gap. ${ }^{18}$ This makes identifying causal connections between workplace exposures and later-developing diseases difficult. Hence, the BLS statistics fail to account for a significant portion of diseases caused by workplace exposures. ${ }^{19}$ One study estimated that BLS data fails to include 66 to $75 \%$ of occupational diseases. ${ }^{20}$ The toxicity data gap also undermines the compensatory goal of the worker safety regime. A 2004 study estimated that over $98 \%$ of deaths caused by occupational disease go uncompensated by the workers' compensation system. ${ }^{21}$

The puzzle, then, is how to correct the market and regulatory failures that have hamstrung the three-pronged workplace safety regime's ability to handle worker disease. This Article solves the puzzle by changing state workers' compensation laws in two ways: (1) imposing a default burden allocation rule favorable to claimants on the question of causation in state workers' compensation proceedings where there is no applicable OSHA exposure limit in place; and (2) expanding current state workers' compensation laws to encompass the manufacturers of chemicals used in the workplace as potential respondents in workers' compensation proceedings.

This proposal is a unique effort to capitalize on the financial incentives of employers and chemical manufacturers-the entities in the best position to produce toxicity information and avoid the expected costs of employee exposures. Because it identifies and corrects the sources of market and regulatory failure, this proposal presents a promising path for reforming the workplace safety regime.

Part II of this Article introduces the status quo occupational exposure regulatory regime through the story of worker exposures to the unregulated chemical diacetyl, including the questionable responses of chemical manufacturers and employers to public pressure and legal claims based on diacetyl exposures. Part III identifies the labor market failure that prevents efficient allocation of risk, precaution, and wages in the context of workplace chemical exposures. Understanding the sources of this market failure is a necessary precedent to meaningful discussion and evaluation of regulatory reform. Part IV explains the regulatory failures-why and how the current workers' compensation and OSHA systems are inadequate to correct the market

${ }^{18}$ See Lin, supra note 1, at 961-62 ("The toxic ignorance problem is the unsurprising result of rational decisions by chemical manufacturers not to conduct extensive testing. Our legal system generally assumes that chemicals are "innocent until proven guilty"; we restrict chemical manufacture and distribution only if and when harm is demonstrated." (footnotes omitted)); Wagner, Commons lgnorance, supra note 17, at 1677-78.

${ }^{19}$ See Viscusi, supra note 4, at 54.

${ }^{20}$ Kenneth D. Rosenman et al., How Much Work-Related Injury and Illness Is Missed by the Current National Surveillance System?, 48 J. Occupational \& ENvTL. Med. 357, 362 (2006).

21 J. Paul Leigh \& John A. Robbins, Occupational Disease and Workers Compensation: Coverage, Costs, and Consequences, 82 MILBANK Q. 689, 703-04 (2004) (finding that workers' compensation programs failed to compensate approximately $98.9 \%$ of the deaths due to occupational disease). 
failures identified in Part III. Part V then briefly considers and evaluates some of the leading proposals for reform that have been offered by other employment and environmental scholars. Part $\mathrm{V}$ demonstrates that none of these proposals adequately utilize the financial incentives of employers and chemical manufacturers, and therefore each proposal would ultimately fall short of correcting the market and regulatory failures at the root of the problem. Part VI sets out in detail the proposed solution: a two-part, incentive-based approach that will spur the production of toxicity information by chemical manufacturers, leading to more effective regulation of workplace exposures. Part VI also details the logistics for implementing the proposal by convening a new National Commission on State Workers' Compensation Laws.

\section{THE DIACETYL STORY}

\section{A. The Discovery of "Popcorn Lung"}

The chemical diacetyl (2,3 butanedione, CAS \# 431-03-8) is an organic chemical that occurs naturally in certain dairy products." 22 Diacetyl can be produced by extracting it from dairy products or by manufacturing it using chemical synthesis. ${ }^{23}$ Diacetyl has long been used as an additive to food flavorings to give foods a dairy, butter, or cheese flavor. ${ }^{24}$ In 1983 , diacetyl was categorized as "generally recognized as safe" by the Food and Drug Administration (FDA). ${ }^{25}$ Diacetyl is best known for its role as the primary component in artificial butter flavorings used in microwave popcorn. ${ }^{26}$

By 1993, at least one manufacturer of diacetyl had some scientific evidence suggesting that diacetyl could have harmful health effects at sufficiently high acute exposure levels. ${ }^{27}$ In 1993, the diacetyl manufacturer BASF conducted a study in which rats were exposed to acute inhalation of pure diacetyl vapor for

${ }^{22}$ Occupational Exposure to Diacetyl and Food Flavorings Containing Diacetyl, 74 Fed. Reg. 3938, 3939 (proposed Jan. 21, 2009) (to be codified at 29 C.F.R. pt. 1910) [hereinafter Proposed Rule for Diacetyl].

${ }^{23} \mathrm{Id}$.

${ }^{24}$ See id; see also Occupational Safety \& Health Admin., Worker Alert: DiACETYL AND SubSTITUTES (2010) [hereinafter OSHA DiACETYL WORKER ALERT], available at $\mathbf{h t t p} / /$ www.osha.gov/SLTC/flavoringlung/diacetyl_worker_alert.pdf.

2521 C.F.R. $\$ 184.1278$ (1983); see also Andrew Scott Dulberg, The Popcorn Lung Case Study: A Recipe for Regulation?, 33 N.Y.U. Rev. L. \& Soc. Change 87, 92 (2009).

${ }^{26}$ See, e.g., Stephen Labaton, OSHA Leaves Worker Safety Largely in Hands of Industry, N.Y. TIMES, Apr. 25, 2007, at A1, available at http://www.nytimes.com/2007/04/ 25/washington/25osha.html?pagewanted=all; Proposed Rule for Diacetyl, supra note 22.

27 See BASF, REPORT: STUDY ON THE ACUTE INHALATION TOXICITy LC50 OF Diacetyl FCC as Vapor in Rats 4-Hour Exposure; Project No. 1310247/9270101 (1993), cited in Letter from Nicholas A. Ashford et al., to Elaine L. Chao, Sec'y of Labor, U.S. Dep't of Labor, at 10 n.20 (July 26, 2006) [hereinafter 2006 Letter], available at http://www.defendingscience.org/sites/default/files/upload/Scientists $\% 20$ Letter $\% 20$ to $\% 200$ SHA\%20on\%20Diacety107262006.pdf. 
one four-hour period. The study found that this exposure led to an "abundance of symptoms indicative for respiratory tract injury." 28 The results of this study were not reported to the government or published in any scientific journals. BASF did not share the results of this study until 2001.29 Even before the BASF study, perhaps as early the mid-1970s, some suspected that exposures to diacetyl caused illnesses. ${ }^{30}$

In 1999, a physician in Missouri diagnosed a worker in a microwave popcorn plant with a condition known as bronchiolitis obliterans (sometimes referred to as "popcorn lung"), a rare and debilitating lung disease that is sometimes fatal. ${ }^{31}$ Missouri health officials contacted the National Institute for Occupational Safety and Health (NIOSH), which began to investigate the plant. ${ }^{32}$ Missouri officials also requested that OSHA inspect the plant. ${ }^{33}$ OSHA inspected the plant but did not take air sample tests; OSHA quickly declared the facility compliant and closed the file. ${ }^{34}$ After an OSHA complaint was filed by a Missouri law firm, OSHA again visited the plant but concluded that further investigation was not warranted. ${ }^{35}$ Instead, OSHA entered into a voluntary partnership agreement in 2002 with a group of popcorn manufacturers. ${ }^{36}$ The purpose was to gather information and, with the assistance of industry, develop a "Hazard Information Bulletin" that would permit the dissemination of information about diacetyl risks to employers and employees. ${ }^{37}$ The agreement terminated in 2003 without the issuance of a hazard bulletin. ${ }^{38}$

In contrast to OSHA's response, NIOSH conducted research at the Missouri microwave popcorn plant and discovered that the workers appeared to have higher incidences of certain lung ailments than expected in the general

282006 Letter, supra note 27 , at 2.

${ }^{29}$ See Dulberg, supra note 25, at 94; 2006 Letter, supra note 27, at 2.

${ }^{30}$ Jesse McKinley, Flavoring-Factory Illnesses Raise Inquiries, N.Y. TIMES, May 6, 2007, at 33, cited in Dulberg, supra note 25, at 92.

31 Dulberg, supra note 25 , at $87-89$.

322006 Letter, supra note 27, at 1 . NIOSH was created by the OSH Act and is part of the federal Centers for Disease Control and Prevention (CDC) in the Department of Health and Human Services. See 29 U.S.C. $\$ 671$ (2006). NIOSH is the research counterpart to OSHA, and is authorized:

(1) to conduct such research and experimental programs as [it] determines are necessary for the development of criteria for new and improved occupational safety and health standards, and (2) after consideration of the results of such research and experimental programs make recommendations concerning new or improved occupational safety and health standards.

29 U.S.C. § 671(d) (2006).

33 Dulberg, supra note 25, at 96 ("In a letter dated May 19, 2000, MDOH requested that OSHA visit Jasper and inspect the Gilster-Mary Lee factory ....").
${ }^{34}$ Id.
${ }^{35} \mathrm{Id}$. at 97.
${ }^{36}$ Id. at 98 .
${ }^{37} \mathrm{Id}$.

${ }^{38} \mathrm{Id}$. 
population. ${ }^{39}$ The results of the NIOSH investigation were published in the Center for Disease Control's (CDC) Morbidity and Mortality Weekly Report ${ }^{40}$ and in the New England Journal of Medicine. ${ }^{4}$

In 2006, the United Food and Commercial Workers International Union and the International Brotherhood of Teamsters petitioned OSHA to adopt an Emergency Temporary Standard (ETS) under the Occupational Safety and Health Act (OSH Act) regulating occupational exposures to diacetyl. ${ }^{42} \mathrm{~A}$ group of forty-two doctors, scientists, and public health experts submitted a letter to the U.S. Secretary of Labor supporting the unions' petition. ${ }^{43}$ One year later, OSHA responded by declining to adopt an ETS. ${ }^{44}$ Edwin G. Foulke Jr., the former Assistant Secretary of Labor for Occupational Safety and Health, explained in an interview that "the science is murky" on whether diacetyl causes bronchiolitis obliterans. ${ }^{45}$

By late 2007, some members of Congress were urging a comprehensive reexamination of diacetyl's effects, in part because of extensive media coverage and new concerns that diacetyl might even cause health problems through consumption of microwave popcorn. ${ }^{46}$ Under pressure from Congress, OSHA declared that it would commence a rulemaking process for diacetyl. ${ }^{47}$ It also issued a Safety and Health Information Bulletin and provided a Hazard Communication Guidance document for employers - some four years after the voluntary partnership agreement failed to produce a Hazard Information Bulletin. ${ }^{48}$ In October 2007, OSHA held a stakeholder meeting to discuss occupational exposures to diacetyl and food flavorings containing diacetyl. In

${ }^{39}$ Dulberg, supra note 25 , at 96.

${ }^{40}$ CTRS. FOR DISEASE CONTROL \& PREVENTION, Fixed Obstructive Lung Disease in a Microwave Popcorn Factory-Missouri, 2000-2002, 51 MORBIDITY \& MORTALITY WKLY. REP., Apr. 26, 2002, at 345-47.

${ }^{41}$ Kathleen Kreiss et al., Clinical Bronchiolitis Obliterans in Workers at a MicrowavePopcorn Plant, 347 NEw ENG. J. MED. 330, 330-38 (2002).

42 Dulberg, supra note 25, at 108.

${ }^{43}$ See 2006 Letter, supra note 27 , at 48.

${ }^{44}$ Letter from Edwin G. Foulke, Jr., Assistant Sec'y for Occupational Safety \& Health, to James Hoffa, Gen. President, Int'l Bhd. of Teamsters (Sept. 25, 2007), cited in Dulberg, supra note 25 , at $108 \mathrm{n} .189$.

${ }^{45}$ Labaton, supra note 26, at A1; see also Dulberg, supra note 25, at 99.

${ }^{46}$ See Dulberg, supra note 25 , at $112-15$. Dulberg considers the manufacturers' response to media pressure a victory, and suggests that the media can play an important role in combating workplace exposures. Id. However, Dulberg's work predates the revelation that the diacetyl substitutes may prove just as harmful - if not more harmful than diacetyl itself. Dulberg may have been overly optimistic about the ability of media coverage to provide an adequate check on industry's economic incentives.

${ }^{47}$ Katherine Torres, OSHA Begins Rulemaking Process on Diacetyl, EHS TODAY (Sept. 25, 2007), http://ehstoday.com/standards/osha/ehs_imp_ 72017.

${ }^{48}$ See generally Hazard Communication Guidance for Diacetyl and Food Flavorings Containing Diacetyl, OcCuPATIONAL SAFETY \& HeAlTH ADMIN., http://www.osha.gov/dsg/ guidance/diacetyl-guidance.html (last visited Nov. 7, 2012) [hereinafter OSHA Diacetyl Hazard Communication]. 
January 2009, OSHA finally issued an Advance Notice of Proposed Rulemaking that sought data, information, and comment on "issues related to occupational exposure to diacetyl and food flavorings containing diacetyl."49 To date, there is no OSHA permissible exposure limit (PEL) standard specifically governing diacetyl or butter flavorings. ${ }^{50}$

OSHA's slow response to the diacetyl issue has been criticized by legal scholars. ${ }^{51}$ Professor Susan Bisom-Rapp argues that OSHA "abandon[ed] its mission" on the diacetyl issue by employing an ineffective strategy that sought to negotiate and coordinate with manufacturers to arrive at voluntary compliance. 52

Injured workers from the plant sought compensation for the damages caused by the exposures by filing workers' compensation claims against their employer pursuant to the applicable state workplace disease law. ${ }^{53}$ As employers often do in workplace disease claims, the employer initially denied the claims and denied liability, contending that the workers' diseases were not caused by workplace exposures to diacetyl. ${ }^{54}$ Some workers turned to tort claims against the manufacturers of diacetyl to seek redress for their injuries. ${ }^{55}$ An early successful jury verdict led to a series of settlements between workers and diacetyl manufacturers. ${ }^{56}$ But the tort system comes with its own efficiency and distributive concerns, as discussed infra Part IV.B, and is not likely the optimal way to address workplace safety and health issues. ${ }^{57}$

The scientific evidence suggesting that inhalation exposure to diacetyl can cause lung damage continues to mount. ${ }^{58}$ Yet, as of this writing, there are not

${ }^{49}$ Proposed Rule for Diacetyl, supra note 22, at 3938. The Advance Notice of Proposed Rulemaking sought information to "assist the Agency in developing a proposed standard addressing occupational exposure to diacetyl and food flavorings containing diacetyl." Id. The Advance Notice of Proposed Rulemaking was later withdrawn so that OSHA could convene a Small Business Advocacy Review Panel, in compliance with the Small Business Regulatory Enforcement Fairness Act, 5 U.S.C. $\$ \S 801-808$ (2006). See 74 Fed. Reg. 11,329 (Mar. 17, 2009).

${ }^{50}$ See Flavorings-Related Lung Disease, Occupational SAFETy \& HEAlth AdMin., $\mathrm{http} / / /$ www.osha.gov/SLTC/flavoringlung/index.html (last visited Aug. 25, 2012).

51 See generally Dulberg, supra note 25. See also DAvid Michaels, DOUBT Is Their ProDuCT 110 (Oxford Univ. Press 2008) (citing the popcorn lung story as evidence that OSHA "has pretty much stopped working"); Susan Bisom-Rapp, What We Learn in Troubled Times: Deregulation and Safe Work in the New Economy, 55 WAYNE L. REV. 1197, 1208-09 (2009).

${ }^{52}$ Bisom-Rapp, supra note 51, at 1238.

53 Dulberg, supra note 25 , at 100 n. 108 .

54 See id.

$55 \mathrm{Id}$. at $99-100$.

${ }^{56}$ See id. at $100-03$.

57 See Viscusi, supra note 4, at 62.

58 OSHA Diacetyl Hazard Communication, supra note 48 ("Recent studies have shown respiratory tract damage and death among rodents exposed to diacetyl and butter flavorings containing diacetyl. Hubbs and co-investigators demonstrated in a preliminary study that exposure of rats to $198.4 \mathrm{ppm}$ of diacetyl for 6 hours caused necrosis of the nasal and 
any permanent, interim, or emergency temporary OSHA standards governing permissible exposure limits or minimum safety precautions for workers potentially exposed to diacetyl. Following the media pressure and concerns about consumer exposures, several major microwave popcorn manufacturers began to replace diacetyl with substitutes in late 2007. Manufacturers began to market their microwave popcorn as "Diacetyl-Free." 59

There is new concern, however, that the diacetyl substitutes may be just as harmful as diacetyl, and that some of them are "actually just another form of diacetyl." $" 60$ In a December 2009 letter, NIOSH indicated that several different potential substitutes for diacetyl, including "starter distillate," acetoin, and 2,3pentanedione, may cause similar adverse health effects because they contain high concentrations of diacetyl itself, have similar structures to diacetyl, or have been inadequately tested. ${ }^{61}$ The Material Safety Data Sheet (MSDS) for 2,3pentanedione illustrates the point, reading: "Toxicological Information: To the best of our knowledge, the chemical/physical/toxicological properties have not been thoroughly investigated." 62

The NIOSH letter discusses ongoing animal studies of 2,3-pentanedione suggesting that the diacetyl substitute causes airway damage similar to diacetyl-perhaps even worse. ${ }^{63}$ The NIOSH letter concludes: "The issues above for starter distallate, acetoin, and 2,3-pentanedione exemplify the lack of evidence demonstrating the workplace safety of potential substitutes for diacetyl; and document some evidence that potential substitutes are also respiratory hazards." 64

tracheal epithelium (Hubbs, et al., 2004). In another preliminary study, exposure of mice to 200 and $400 \mathrm{ppm}$ diacetyl via inhalation for 6 hours per day over 5 days caused death, acute necrotizing rhinitis, and erosive or necrotizing laryngitis (Morgan, 2006).").

${ }^{59}$ Andrew Schneider, Just When You Thought It Was Safe to Make Popcorn, AOLNEws (Dec. 10, 2009), www.aolnews.com/2009/12/10/just-when-you-thought-it-wassafe-to-make-popcorn.

${ }^{60} \mathrm{Id}$.; see also OSHA DIACETYL WORKER ALERT, supra note 24 ("Diacetyl substitutes that have not been proven to be safe include diacetyl trimer, 2,3 hexanedione, 2,3 heptanedione, and 2,3 pentanedione.").

${ }^{61}$ Letter from John Howard, Dir. of NIOSH, to David Michaels, Assistant Sec'y of Labor for Occupational Health (Dec. 23, 2009) [hereinafter Howard Letter], available at http://defendingscience.org/sites/default/files/upload/Howard_Letter_on_Diacetyl_

Substitutes.pdf.

62 Lansdowne Aromatics, Safety Data Sheet: 2,3-Pentanedione 2 (2009), available at http://www.lansdownearomatics.com/assets/Naturals-pdf/2,3-PENTANEDI ONE.pdf. MSDS's are provided by employers to workers pursuant to OSHA's Hazard Communication Standard. See infra Part IV.D.

${ }^{63}$ Howard Letter, supra note 61.

${ }^{64} \mathrm{Id}$. In fact, exposures to 2,3 pentanedione may actually be worse for employees' health than exposures to diacetyl. According to one toxicologist in NIOSH's Health Effects Laboratory Division, "Pentanedione is a little less water-soluble, so it might be better able to reach the deep lung." Anietra Hamper, Butter-Flavor Substitutes Also Raise Alarms, Columbus DisPatch, May 12, 2010, at A6. 
Meanwhile, microwave popcorn is currently being manufactured using diacetyl substitutes and marketed to the public as "Diacetyl Free" or as containing "No Added Diacetyl." 65 The exact chemical mixtures used in place of diacetyl cannot be known with certainty because the popcorn manufacturers assert that their recipes are protected trade secrets. ${ }^{66}$ It is likely, however, that manufacturers are using the known substitutes that NIOSH expressed concern about, including 2,3 pentanedione. NIOSH does not know for certain, and neither do the employees currently working in microwave popcorn plants. In fact, many employers do not even know the chemical ingredients of the diacetyl substitutes they are using in the food manufacturing process. ${ }^{67}$

\section{B. Diacetyl and Recurring Themes in Chemical Exposure Cases}

\section{Innocent Until Proven Guilty}

The diacetyl story is not yet concluded, but it follows a familiar plot line for chemical exposure cases. Under our environmental and worker safety regulations, chemicals are generally presumed to be safe unless and until proven otherwise. At the beginning of the story, toxicity studies or other information suggesting potential harmful effects may be in the hands of chemical manufacturers, but it is not turned over to the government or disclosed to employees. ${ }^{68}$ The scientific understanding of the effects of exposure to a particular chemical or substance eventually evolves-usually due to clusters of observed human illnesses-but it often comes too late to prevent a significant

${ }^{65}$ See supra note 59 and accompanying text; see also Press Release, ConAgra Foods,

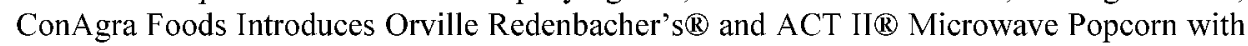
a New Great Tasting Butter Flavoring with No Added Diacetyl (Dec. 17, 2007), available at $\mathrm{http} / /$ media.conagrafoods.com/phoenix.zhtml?c=202310\&p=irol-newsArticle\&ID=1087864 \&highlight $=$.

${ }^{66}$ Schneider, supra note 59 ("Those companies, citing competition, repeatedly refuse to discuss what they're using today to add the butter flavor to what they sell."); see also Hamper, supra note 64, at A7 ("At the [NIOSH] lab in West Virginia, researchers say they don't have a good handle on all of the diacetyl substitutes now in use because of the reluctance of some food producers to reveal trade secrets.").

${ }^{67}$ Hamper, supra note 64, at A7 ("Dr. Kay Kreiss, who investigates health-hazard complaints for the institute, said that in many instances, food manufacturers themselves don't know what diacetyl substitutes are in the flavorings they buy."); see also Diacetyl and Food Flavorings Containing Diacetyl: Stakeholder Meeting, Summary Report, OCCUPATIONAL SAFETY \& HEALTH ADMIN. (Nov. 27, 2007), www.osha.gov/dsg/guidance /101707-diacetyl-meeting-notes.html ("A few stakeholders noted that material safety data sheets (MSDSs) frequently do not include detailed information on flavorings because the flavoring constituents are proprietary. Some smaller food manufacturers, therefore, might not be aware of exposures concerns.").

68 See Thomas O. MCGarity \& Wendy E. Wagner, Bending SCIENCE: How SPECIAL INTERESTS CORRUPT PUBLIC HEALTH RESEARCH 97, 103 (2008). 
number of serious and debilitating illnesses. ${ }^{69}$ Initially, employers may deny causation and dispute workers' compensation claims. ${ }^{70}$ Some workers who are denied compensation through the workers' compensation system will seek other avenues of recovery, including tort claims against chemical manufacturers or other third parties, where possible. ${ }^{71}$

Command and control regulations from OSHA come slowly, if at all, because of the dearth of information on toxicity and available precautions. ${ }^{72}$ If enough information finally begins to mount implicating the chemical, then chemical manufacturers and employers will scramble to find substitutes. These chemical substitutes often present their own unquantified health risks. ${ }^{73}$ Toxicity information on substitutes may be underdeveloped, and manufacturers often assert trade secret protection over new chemicals and mixtures. ${ }^{74}$ This cycle may repeat for the substitutes, leading to the introduction of even more chemical substitutes.

Our three-pronged worker safety regime struggles to regulate the uncertain risks caused by exposures and generally fails to compensate employees that may have been harmed by prior exposures. The microwave popcorn workers likely did not receive a compensating wage differential ex ante because the science on diacetyl exposures had not yet been developed at the time the workers negotiated their wages. As for ex post compensation, the employers (at least initially) denied workers' compensation claims on the grounds of causation. ${ }^{75}$ Some employees were able to recover ex post compensation from tort claims against the chemical manufacturers, but this outcome is rare, as explained further below. ${ }^{76}$

Aspects of the diacetyl storyline closely parallel our prior experiences with other workplace exposures to hazardous substances and materials. Probably the most famous example is asbestos fiber, originally thought to be a relatively safe

${ }^{69}$ See Lin, supra note 1, at 957 ("Experiences in which we have discovered the hazards of chemical substances belatedly-ranging from asbestos to benzene to polychlorinated biphenyls (PCBs) - illustrate the potentially broad and serious consequences of toxic ignorance.").

70 MICHAELS, supra note 51 , at 227-28.

${ }^{71}$ Id. at 223; Martha T. McCluskey, The Illusion of Efficiency in Workers' Compensation "Reform," 50 RUTGERs L. REV. 657, 903 (1998).

${ }_{72}$ Michaels, supra note 51, at 223; Is OSHA Working?, supra note 3 , at $8-11,13$ (statement of David Michaels, Ph.D., Research Director and Associate Chairman of the Department of Environmental and Occupational Health, George Washington University, Washington, D.C.).

${ }^{73}$ See infra Part II.B.2. Examples provided below regarding TCE-TCA-Freon-Vertrel substitutions.

${ }^{74}$ See MCGARITY \& WAGNER, supra note 68 , at 110 . For a discussion of Vertrel, see infra Part II.B.2.

${ }^{75}$ See supra notes 53-54 and accompanying text.

${ }^{76}$ See infra Part IV.B. 
insulator and fire-repellant. ${ }^{77} \mathrm{After}$ it was too late, we learned that exposure to asbestos caused thousands of workers to contract mesothelioma, asbestosis, or lung cancer. ${ }^{78}$ Many victims are now paid pennies on the dollar out of special trust funds set up for asbestos exposure victims following the bankruptcy of asbestos manufacturers, and the tort system's resolution of asbestos claims is generally considered to be a "dismal failure."79

Industry resistance to command and control regulations is also a recurrent theme in these cases. Industry groups long resisted the adoption of OSHA regulations governing exposures to lead, mercury, silica dust, and other hazardous substances. ${ }^{80}$ As with diacetyl, their strategy was largely based on emphasizing scientific doubts about causation, in order to capitalize on the "innocent until proven guilty" system of chemical regulation in the U.S. ${ }^{81}$

\section{Chemical Substitutions}

The chemical-substitution theme is also familiar. The evolution of the industrial chemical solvent degreaser industry provides another illustration of the chemical substitution pattern. The chemical trichloroethylene (TCE), a volatile organic chemical, was widely used as a degreaser in the manufacture of electronic circuits and components until concerns about TCE's environmental effects led the industry to replace it with trichloroethane (TCA), which has a similar chemical structure. ${ }^{82}$ TCE and TCA were among the most widely used

${ }^{77}$ See Laura Hall et al., Litigating Toxic Risks Ahead of Regulation: Biomonitoring Science in the Courtroom, 31 STAN. ENVTL. L.J. 3, 42 (2012) (citing asbestos, lead, and DDT as examples of toxins once thought to be safe); Frank J. Macchiarola, The Manville Personal Injury Settlement Trust: Lessons for the Future, 17 CARDOzO L. REV. 583, 588 (1996) (noting the properties and uses of asbestos); Richard A. Solomon, Comment, Clearing the Air: Resolving the Asbestos Personal Injury Litigation Crisis, 2 FORDHAM ENVTL. L. REV. 125, 126-27 (1991) (describing the various applications of asbestos).

${ }^{78}$ See Macchiarola, supra note 77 , at 588-89 (describing the ailments caused by exposure to asbestos); David Rosenberg, Book Review, The Dusting of America: A Story of Asbestos-Carnage, Cover-Up, and Litigation, 99 HARv. L. REv. 1693, 1693 (1986) ("Hundreds of thousands of these people have died or are dying from asbestos-related diseases: asbestosis, mesothelioma, and lung cancer.").

${ }^{79}$ See Joshua M. Silverstein, Overlooking Tort Claimants' Best Interests: Non-Debtor Releases in Asbestos Bankruptcies, 78 UMKC L. REV. 1, 96-97, n.548 (2009) (quoting James L. Stengel, The Asbestos End-Game, 62 N.Y.U. ANN. SurV. AM. L. 223, 262 (2006)).

${ }^{80}$ McCluskey, supra note 71 , at 772 .

81 Id. at 772; see also MICHAELS, supra note 51, at 95 (discussing aromatic amines, and stating, "Instead, the corporations' modus operandi was the same as it always is. Attack the science. Ignore the science. Demand of the science something neither it nor any institution possesses: absolute certainty.").

82 See Richard E. Doherty, A History of the Production and Use of Carbon Tetrachloride, Tetrachloroethylene, Trichloroethylene, and 1,1,1-Trichloroethane in the United States: Part 2-Trichloroethylene and 1,1,1-Trichloroethane, 1 J. ENVTL. ForENSICS $83,83,87-88(2000)$. The use of TCA as a degreaser required the addition of a new type of stabilizer to prevent reactions leading to corrosive byproducts. $I d$. at 90 . The chemical 1,4 
industrial degreasers, and they are now found in many of the hazardous cleanup sites listed on the National Priorities List. ${ }^{83}$ TCA, in turn, was replaced as a degreaser by chlorofluorocarbons such as Freon when ozone depletion concerns were raised about TCA in the $1990 \mathrm{~s} .{ }^{84}$ The use of Freon as a chemical degreaser was eventually phased out due to its own health and environmental concerns. ${ }^{85}$ Now, new mixtures of solvents are being used in vapor degreasing. DuPont has introduced a line of chemical degreasers under the brand name Vertrel that includes the mixture of a well-known chlorinated solvent, trans 1,2 dichloroethylene (trans-1,2 DCE), and a DuPont-patented fluorocarbon known as HFC-43-10mee. ${ }^{86}$ HFC-43-10mee has been the subject of some toxicity testing, including some genetic testing, and DuPont claims that these studies demonstrate its low toxicity. ${ }^{87}$ Based on the testing, DuPont has recommended certain acceptable exposure limits for HFC-43-10mee, but these suggested limits have not been verified, ${ }^{88}$ and OSHA has not yet adopted a PEL for the chemical. 89

The substitution of new chemicals in the manufacture of degreasing solvents might be thought to represent an admirable desire to replace chemicals that pose dangers to human health or to the environment with safer chemicals. But the history of chemical manufacturer action and inaction shows that chemical companies will generally resist phase-outs of profitable chemicals

dioxane became a widely-used TCA stabilizer, and 1,4 dioxane itself is now suspected of presenting its own environmental and health concerns. See generally ENVTL. PROT. AGENCY, OPPT Chemical Fact SheEt, 1,4 Dioxane Fact SheEt: Support Documtn (CAS No. 123-9-1) (1995).

${ }^{83}$ See Doherty, supra note 82 , at 83,87 . As of 1997 , TCE was reported as being present at 852 of 1438 National Priority List sites. $I d$. at 83 . TCA was "by far the most used, easiest, and efficient cleaning solvent." Id. at 87-88 (quoting a spokesman for the chemical industry).

${ }^{84}$ Id. at 91 (noting that TCA was still used as an intermediate product because "many potential CFC replacements used TCA as a feedstock").

${ }^{85}$ See MiCHAELS, supra note 51, at 45 (describing the efforts of DuPont to attack the science implicating Freon in ozone depletion prior to governmental action to ban fluorocarbons).

${ }^{86}$ The fluorocarbon HFC-43-10mee is also known as $1,1,1,2,2,3,4,5,5,5-$ decafluoropentane, CAS No. 138495-42-8. See DUPONT, MSDS FOR VETREL SDG Specialty Fluid 2 (2011) [hereinafter MSDS FOR Vetrel SDG SPecialty Fluid], available at $\mathrm{http} / / \mathrm{msds}$.dupont.com/msds/pdfs/EN/PEN 09004a35804fa7a7.pdf. The MSDS for each product in the Vertrel line of specialty fluids are available at http:/www2.dupont.com/Vertrel/en_US/tech_info/msds.html. Vertrel is a registered trademark of E.I. duPont de Nemours and Company.

87 See, e.g., MSDS FOR VETREL SDG SPECIALTY FLUID, supra note 86, at 7-8.

88 See Australian NAT'L Indus. Chems. Notification \& ASSESSMENT SChEME, Full PUBliC REPORT ON HFC-43-10MEE40 (1999), available at http://www.nicnas.gov.au/ publications/car/new/na/nafullr/na0600fr/na626fr.pdf.

${ }^{89}$ See MSDS FOR VETREL SDG SPECIALTY FLUID, supra note 86. 
until a suitable (and patented) substitute is discovered. ${ }^{90}$ At that point, the substitute is advertised as "safe," even when toxicity information is insufficient for regulators to confidently draw that conclusion.

\section{Assertion of Trade Secret Protection}

The assertion of trade secret protection as a block to information generation and transparency is another familiar theme. ${ }^{91}$ The OSHA Hazard Communication Standard expressly permits a manufacturer to withhold from a Material Safety Data Sheet (MSDS) the chemical ingredients or composition of a substance, under certain conditions, if the manufacturer asserts a trade secret protection over that information. ${ }^{92}$ The effect of this roadblock was recently publicized in the response to the Deepwater Horizon oil well failure in the Gulf of Mexico. In the initial response to the spill, chemical dispersants called Corexit 9527A and Corexit 9500A were used to disperse crude oil leaking from the failed well. ${ }^{93}$ The dispersants were used directly on the surface of the spill,

${ }^{90}$ The chemical substitution strategy is not limited to U.S. industry. The now-Assistant Secretary of Labor for Occupational Safety and Health, David Michaels, provides another example of dubious chemical substitution in the British rubber industry in response to cancer outbreaks among workers exposed to the chemical beta-Napthylamine (BNA). See MICHAELS, supra note 51, at 26 (after eliminating the use of BNA, the British rubber industry "continued to rely on other aromatic amines as antioxidants, several of which were later determined to be bladder carcinogens, and rubber workers paid for this practice with increased risk of bladder cancer for years").

91 This may include assertions of trade secret protection over scientific information in a manufacturer's possession, such as internal research studies (like the one conducted by BASF on diacetyl in 1993) suggesting that a product has unexpected health risks. See MCGARITY \& WAGNER, supra note 68, at 97; see also CARL F. CRANOR, LEGALLY POISONED: HOW THE LAW PUTS US AT RISK FROM TOXICANTS 6 (2011) ("Of the approximately 50,000 new substances introduced since 1979, about eighty-five percent had no data concerning health effects; even the chemical identity of a majority of them is veiled by claims of confidential business information. At current rates, testing these products after they are already in commerce could take hundreds of years.").

92 OSHA Hazard Communication, 29 C.F.R. $\$ 1910.1200$ (2011). On March 26, 2012, OSHA published a final rule revising the Hazard Communication Standard. See 77 Fed. Reg. 17,574 (Mar. 26, 2012). The most significant revision to the standard was the adoption of the United Nations Globally Harmonized System of Classification and Labeling of Chemicals (GHS), Revision 3. See id. The revised standard also requires that safety data sheets include certain enumerated sections and headings. See 29 C.F.R. $\$ 1910.1200(\mathrm{~g})$ (2012). Chemical manufacturers and employers must comply with most of the revised provisions of the rule by June 1, 2015. See id. $\$ 1910.1200(j)$. The revised standard retains, with no modifications material to this discussion, provisions permitting employers and chemical manufacturers to withhold information about specific chemical identities and concentrations under an assertion of trade secret protection. See id. $\$ 1910.1200(\mathrm{i})$.

${ }^{93}$ See Elana Schor, Ingredients of Controversial Dispersants Used on Gulf Spill Are Secrets No More, N.Y. TIMES, Jun. 9, 2010, http://www.nytimes.com/gwire/2010/06/09/ 
as well as underwater. ${ }^{94}$ Corexit $9527 \mathrm{~A}$ was used in early response efforts. ${ }^{95}$ When initial concerns arose about Corexit 9527A's potential toxicity to the ecosystem and to workers exposed to the substance during surface operations, it was replaced by Corexit $9500 \mathrm{~A} .96$ Nalco Holding Co., the manufacturer of Corexit, initially asserted that the chemical compositions of the Corexit dispersants were trade secrets. ${ }^{97}$ Only after public pressure (and potential worker exposures) did the EPA ultimately release the specific chemical components in the two versions of Corexit. ${ }^{98}$ The health effects of exposure to either version of Corexit, along with their environmental effects, remain largely unknown. ${ }^{99}$ The manufacturer's MSDS for Corexit $9500 \mathrm{~A}$ provides that "[n]o toxicity studies have been conducted on this product." 100 After cleanup efforts began in the Gulf, the EPA began independent toxicity testing on the Corexit dispersants. ${ }^{101}$ According to the EPA, initial toxicity testing results suggest that the Corexit dispersants are "no more or less toxic than the other available alternatives." 102

\section{Unique Aspects of the Diacetyl Story}

Although similar themes tend to recur in chemical exposure stories, each story also contains some unique aspects. Certain characteristics of diacetyl

09greenwire-ingredients-of-controversial-dispersants-used-42891.html; see also U.S. Envtl. Protect. Agency, Press Conference Call 19-22 (May 12, 2010) [hereinafter EPA Conference Call], available at http://www.epa.gov/bpspilldispersants/may 12transcript-final.pdf.

${ }_{94}$ EPA Conference Call, supra note 93.

95 See Schor, supra note 93.

96 The chemical 2-butoxyethanol, an ingredient in Corexit 9527 A, has been linked to "lingering health problems experienced by cleanup workers after the 1989 Exxon Valdez oil spill." Id. One of the newly-revealed chemical ingredients of Corexit is dioctyl sodium sulfosuccinate, "a detergent and common ingredient in laxatives." Id.

${ }^{97}$ See id.

${ }^{98}$ See id. Although the disclosure of the purportedly proprietary ingredients in Corexit will allow independent researchers to begin studying the long and short term risks of the chemicals to potentially exposed workers, see id. (quoting Sen. Kirsten Gillibrand), the disclosure will likely have only a limited effect because of the time needed to conduct the testing. See id. (quoting David Andrews, Senior Scientist at Environmental Working Group). Additionally, the EPA disclosure did not include a description of the proportions in which the chemical ingredients are used to make Corexit products. Id.

${ }^{99}$ See generally Questions and Answers on Dispersants, Envtl. PRotect. AGency, http:/www.epa.gov/bpspill/dispersants-qanda.html\#effects (last visited Jun. 29, 2012) (noting that "long term effects on aquatic life are unknown" and, with respect to human health effects, referring to the Corexit MSDS).

100 Nalco, Material SAFETy Data SheEt: Product COREXIt® EC9500A 5 (2008), available at http:/thepumphandle.files.wordpress.com $/ 2010 / 05 /$ corexit-9500a-msds.pdf.

101 See EPA Response to BP Spill in the Gulf of Mexico: Questions and Answers on Dispersants, ENVTL. PROTECT. AGENCY, http://www.epa.gov/bpspill/dispersants-qanda.html (last updated Oct. 14, 2011).

${ }^{102} I d$. 
exposure made proof of causation in tort suits somewhat less difficult for the microwave popcorn employees than it typically is in chemical exposure cases. First, the onset of bronchiolitis obliterans did not follow a long latency period. Workers showed symptoms after a median of a year and a half of exposure in the workplace. ${ }^{103}$ Many cancers caused by chemical exposures are characterized by long induction and latency periods, such that the cancer takes much longer to detect. ${ }^{104}$ Second, the specific disease at issue, bronchiolitis obliterans, is rare and is sometimes characterized as a "signature disease" that is traceable to exposure to diacetyl. ${ }^{105}$ Smoking, which is often blamed by employers for workers' contraction of respiratory ailments, cannot cause bronchiolitis obliterans. ${ }^{106}$ For these reasons, it proved easier than usual to directly connect the chemical diacetyl to the workers' respiratory diseases. It was easier for the diacetyl workers to convince their employers to stop denying workers' compensation claims and to extract tort settlements from diacetyl manufacturers than it is for claimants in the typical workplace exposure case. At least one study suggests that most victims of occupational disease never obtain compensation through the workers' compensation system; according to the 2004 study, workers' compensation fails to compensate an estimated $98.9 \%$ of deaths due to occupational diseases. 107

The diacetyl story is just one illustration of how our three-pronged worker safety regime fails to produce efficient levels of risk, precaution, and compensation for injury. Disease caused by occupational exposures will remain a concern as long as we continue to innovate, discover new processes, and develop and market new chemical compounds. ${ }^{108}$

${ }^{103}$ See Dulberg, supra note 25, at 106 n.173.

104 See CRANOR, supra note 91, at 57.

105 See Dulberg, supra note 25 , at 105 . Another signature disease unique to a particular exposure is mesothelioma, which is caused only by exposure to asbestos. See MiCHAELS, supra note 51, at 61-62 (noting that other than the "few very rare instances" of signature diseases, "epidemiologists cannot state that a specific chemical exposure has definitely caused the cancer of a specific patient").

106 See Dulberg, supra note 25, at 105-06; see also MiCHAELs, supra note 51, at 62 ("The lung cancer from asbestos is indistinguishable from the lung cancer from smoking."); $i d$. at 177 (discussing abestos manufacturers blaming tobacco for lung ailments as part of asbestos litigation).

107 See Leigh \& Robbins, supra note 21, at 703.

${ }^{108}$ For example, the development of nanotechnology threatens to widen the information gap dramatically. See Lin, supra note 1, at 960 ("With the commercialization of nanotechnology, a rapidly developing field that is creating substances with new physical and chemical properties and often unknown toxicological effects, the information gap threatens to expand into an information chasm."); see also Paul C. Sarahan, Nanotechnology Safety: A Framework for Identifying and Complying with Workplace Safety Requirements, 5 NANOTECH. L. \& BUS. 191, 191 (2008). 


\section{Market FaILURE}

Scholars have identified the likelihood of market failure in the context of worker safety generally 109 and workplace disease in particular. ${ }^{110}$ To demonstrate the challenges that proposed reform to the workplace safety regime must overcome, this Part identifies two types of market failure that justify regulatory intervention. First, the labor market is unable to set accurate compensating wage differentials for workers accepting riskier work when workers have inadequate access to information about the risk. ${ }^{111}$ Second, unique characteristics of workplace diseases create negative externalities that allow employers to foist some of the expected costs of workplace disease onto others-including workers, health insurance providers, and the government (and therefore, indirectly, taxpayers in general).

\section{A. Information Failures Preclude Efficient Ex Ante Wage Differentials}

The first prong of the current regime relies on the labor market to set efficient compensating wage differentials for riskier jobs. ${ }^{112}$ There is some evidence of compensating wage differentials in the context of workplace accidents and on-the-job fatalities. One recent estimate found that wages increase about $1 \%$ for workers who accept jobs where the risk of fatality is double the average risk of workplace fatality. 113 There remain questions about whether the wage differentials demanded by employees for dangerous jobs tend to be systematically too low or too high. ${ }^{114}$

Whether or not the market is capable of setting accurate and efficient wage differentials for workplace accidents and on-the-job fatalities, it certainly fares

${ }^{109}$ See Lambert, supra note 9 , at 1015.

110 See Viscusi, supra note 4, at 57-59.

111 See Lambert, supra note 9, at 1024; Viscusi, supra note 4, at 57-59.

112 See McGarity, supra note 9, at 100 ("Under this theory, workers will demand higher wages to work under risky conditions and employers will have a natural incentive to install risk-reduction technologies in dangerous workplaces. Over the long haul, the economy should reach an equilibrium in which workers who consent to working under risky conditions perform the dangerous jobs and employers install the optimum amount of risk reduction technology." (footnote omitted)).

113 See Ronald G. Ehrenberg \& Robert S. Smith, Modern LABOR ECONOMics 245 (9th ed. 2006).

114 Compare Susan Rose-Ackerman, Rethinking the Progressive Agenda: The Reform of THE American Regulatory State 86-88 (1992) (arguing that information problems, employers' monopsony powers, and workers' underestimation of the costs of injury can lead to inadequate compensating wage differentials), and Peter Dorman \& Paul Hagstrom, Wage Compensation for Dangerous Work Revisited, 52 Indus. \& LAB. REL. REV. 116, 116 (1998), with Michael J. MOORE \& W. Kip Viscusi, Compensation Mechanisms FOR JOB RISKS 74-75 (1990) (arguing that workers' estimates of risk generally correlate with BLS statistics and that, if anything, workers tend to overestimate small probabilities of risk, which may lead to compensating wage differentials that are too high). 
poorly in the context of workplace diseases. As Professor W. Kip Viscusi notes, "Informational inadequacies and externalities associated with occupational disease make the free market particularly ineffective in reducing occupational disease risks and compensating disease victims."115 Employees generally cannot observe the risks of exposures to chemicals and substances in the workplace. For example, empirical studies found that workers in the asbestos industry received no compensating wage premiums. ${ }^{116}$ In part, this is due to workers' lack of knowledge about the chemicals used. But even if workers knew exactly what chemicals and substances were used in the plant, they would still not have sufficient information about levels of exposure or the doseresponse data that could indicate the dangers of exposure. Individual employees have no way to evaluate the dangers of exposure and are not in a position to conduct toxicity or epidemiological studies on each chemical in order to evaluate the risks.

Labor unions could mitigate this information problem, to some degree, by combining the resources of many employees and developing and employing scientific expertise. They can demand that the employer provide safety data and coordinate or even fund scientific studies. The diacetyl case highlights the potential role for unions, but also demonstrates the difficulty that unions face. In the case of diacetyl, labor unions urged OSHA and other regulators to take action to protect employees. ${ }^{117}$ Despite union pressure, OSHA refused to adopt an emergency temporary standard in light of the relative dearth of scientific information on diacetyl and only recently began the process of considering a permanent standard for diacetyl exposure. 118 Further, union membership continues to decline; unions now represent less than $12 \%$ of the workforce. ${ }^{119}$ If this trend continues, organized labor will not have the resources to generate the

115 Viscusi, supra note 4, at 57-58 (footnote omitted); see also McCluskey, supra note 71 , at 773 ("Most commentators assume that workers generally will have more difficulty bargaining for wage premiums to compensate for occupational diseases than for the paradigmatic industrial accident because of workers' greater difficulty in obtaining timely and accurate information about the risks of diseases." (citing, among others, NicHOLAS A.

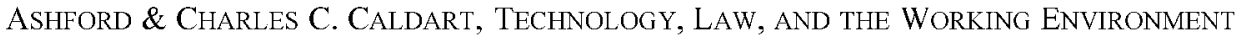
226-28 (1991))).

116 McCluskey, supra note 71 , at 774 (citing MT. Sinai Sch. OF MED., Disability COMPEnSATION FOR Asbestos Associated Disease in THE United STATES, 577-85 (Irving J. Selikoff ed., 1982)).

${ }^{117}$ Letter from Joseph T. Hansen, Int'l President, United Food \& Commercial Workers Int'l Union, and James P. Hoffa, Gen. President, Int'l Bhd. of Teamsters, to Elaine L. Chao, Sec'y of Labor, U.S. Dep't of Labor (July 26, 2006).

118 See supra note 49 and accompanying text.

${ }^{119}$ Zev J. Eigen \& David Sherwyn, A Moral/Contractual Approach to Labor Law Reform, 63 HASTINGS L.J. 695, 700 (2012). 
information necessary to help the free market achieve efficient levels of risk and precaution. ${ }^{120}$

\section{B. Negative Externalities Prevent the Efficient Imposition of Ex Post Compensation Costs on Employers}

The labor market fails to set efficient levels of risk and precaution for a second reason: employers are able to externalize much of the expected costs of risky behavior, and therefore do not take those expected costs into consideration when adjusting their risk and precaution levels. If the labor market were efficient, employers would set the level of precaution at the point where the marginal cost of an additional unit of precaution exactly equals the marginal benefit to the employer in avoiding costs from worker injury or disease, leading to the optimal distribution of risk and precaution. If employers can externalize a sizable portion of their expected costs from worker disease, then they will systematically take too little precaution.

Professor Thomas Lambert contends that this market failure in workplace safety regulation is limited to the systematic informational inadequacy outlined in the preceding section, and that there is no technological negative externality permitting employers to foist some costs of risk onto others. ${ }^{121}$ Professor Lambert claims that costs that appear to be imposed on workers from workplace injuries are actually internalized by the employer via the price mechanism for labor, through the combined labor price components of ex ante compensating wage differentials (discussed above) and the payment of ex post compensation for injuries. ${ }^{122}$ In other words, Professor Lambert acknowledges the information problem preventing workers from negotiating ex ante wage differentials, but believes that a workable solution to that information problem would fully right the ship. For the reasons that follow, Professor Lambert's view is too optimistic - at least as to chemical exposures.

Absent a workers' compensation system, employees would be required to seek ex post compensation for injuries or illnesses via the tort system, and the amount of ex post costs actually borne by the employer would be dependent upon the efficacy of the tort system in setting appropriate and efficient liability rules. Under our current workers' compensation system, including the common use of workers' compensation insurance, employers typically bear any ex post costs in the form of increased workers' compensation insurance premiums. In other words, the additional insurance premium that relatively risky employers pay for workers' compensation insurance will theoretically lead employers to internalize the expected costs of injury and accordingly set efficient risk and

${ }^{120}$ See Viscusi, supra note 4, at 59 ("Unions can have only a limited effect on the occupational health problem, however, since they represent only about twenty percent of the nation's workers.").

${ }^{121}$ Lambert, supra note 9, at 1009 (contending that "the primary market failure with respect to hazardous substances in the workplace is inadequate information").

${ }^{122}$ Lambert, supra note 9, at 1017-24. 
precaution levels. Professor Lambert acknowledges some potential "leaks" in the current workers' compensation system that will permit some residual externalization of ex post costs by the employer, including: imperfect insurance pricing; the costs of litigating and adjudicating workers' compensation claims (some of which is borne by others, including the claimant and the government); the systematic under-compensation of claims due to statutory damage caps and restrictions on certain types of damages, including pain and suffering; and the administrative costs borne by taxpayers in connection with state-administered specialized funds for certain types of easily identified worker injuries. ${ }^{123}$ But, argues Lambert, "economic theory and empirical evidence suggest that the other adjustable element of worker price, worker wages, works in tandem with workers' compensation to ensure that leaks in the injury compensation scheme do not create technological negative externalities that necessitate substantive safety standards." 124 Where compensation benefits are low, workers will demand higher risk premiums, and vice versa, allowing the two components to complement each other. ${ }^{125}$

Professor Lambert's claim has some force with respect to workplace accidents, injuries, and on-the-job fatalities. Empirical studies suggest that workers do receive a compensating wage differential for taking jobs that are objectively risky ${ }^{126}$ or perceived to be risky. ${ }^{127}$ For ordinary workplace injuries, these risk premiums might arguably make up for the leaks Professor Lambert acknowledges in the workers' compensation system-at least roughly. But on the question of technological negative externalities, Professor Lambert overlooks the significant potential for negative externalities caused by certain unique characteristics of workplace disease. Employee access to information is not the only problem in the context of worker disease. Three characteristics of workplace disease lead to technological negative externalities that are not cured simply by employee access to information:

(1) The typical lack of scientific evidence that exposure to a chemical or substance at a given level causes the development of a particular disease makes proof of causation difficult for employees and often prevents any ex post compensation for the disease.

(2) Even where a chemical or substance is recognized as a potential cause, the lack of scientific understanding regarding the significance of

${ }^{123}$ Id. at $1019-20$.

${ }^{124} \mathrm{Id}$. at 1021 . This argument highlights the importance of correcting the market failure that Professor Lambert does acknowledge, incomplete information, to ensure that compensating wage differentials fully internalize for the employer the costs imposed by the identified leaks in the ex post compensation scheme.

${ }^{125} \mathrm{Id}$. at $1022-23$.

126 See, e.g., W. Kip Viscusi, Risk By Choice: Regulating Health and SAfety in THE WORKPLACE 44 (1983) (risk premiums for objectively risky jobs).

127 W. Kip Viscusi, EMPLOYMENT HazARDS: AN InVESTIGATION OF MARKET PERFORMANCE 263 (1979) (concluding that employees in occupations perceived to be risky receive a compensating wage differential). 
potential contributing factors to the disease, such as genetic predisposition, cigarette smoking, and eating habits, often further complicates the causation issue. This provides employers with plausible defenses to compensation claims, preventing ex post compensation. ${ }^{128}$

(3) Many workplace diseases manifest themselves only after a long latency period, further compounding the causation difficulties and making it difficult to connect the costs of any particular worker's disease with a particular employer's prior risk-taking behavior. Long latency periods may also trigger limitations defenses under some state workers' compensation statutes, preventing the employer from internalizing the costs of worker disease. ${ }^{129}$

Because of these unique characteristics, the ex post workers' compensation scheme breaks down for many workplace diseases caused by exposures to hazardous chemicals or substances. ${ }^{130}$ Employers are able to externalize much of the expected costs of workplace disease onto other individuals or groups, including the workers, their families, social security taxpayers, health insurance premium payers, and members of industry-wide insurance pools. ${ }^{131}$ The available empirical evidence confirms this. Studies of the costs of workplace diseases suggest that employers benefit from a large negative externality;

128 Viscusi, supra note 4, at 54 ("Although well-defined scientific relationships exist in some instances, most diseases may be caused by exposure to any one of several substances, or by participation in any one of several activities." (footnote omitted)); see also Ellen R. Peirce \& Terry Morehead Dworkin, Workers' Compensation and Occupational Disease: A Return to Original Intent, 67 OR. L. REv. 649, 650-51 (1988) (describing "dual causation" cases and arguing that the failure of apportionment can thwart the objectives or workers' compensation).

${ }^{129}$ See Michael D. Green, The Paradox of Statutes of Limitations in Toxic Substances Litigation, 76 CALIF. L. REV. 965, 969, 973 (1988) (discussing the successful use of statute of limitations defenses in asbestos cases); Laura Rowinski, Comment, Genetic Testing in the Workplace, 4 J. CONTEMP. HEAlTH L. \& POL'Y 375, 391-92 (1988) (examining the effect of workers' compensation limitation provisions on worker disease claims); Viscusi, supra note 4, at 63. See generally Jordan H. Leibman \& Terry Morehead Dworkin, Time Limitations Under State Occupational Disease Acts, 36 HASTINGS L.J. 287, 303-43 (1985) (providing a comprehensive survey of the treatment of "delayed manifestation occupational diseases" under the limitations provisions of various state workers' compensation statutes).

${ }^{130}$ See Peirce \& Dworkin, supra note 128, at 679.

${ }^{131}$ Viscusi, supra note 4, at 59 n.33 (citing Albert Nichols \& Richard Zeckhauser, OSHA After a Decade: A Time for Reason, in Case Studies in Regulation: Revolution AND REFORM 202, 208-09 (Leonard W. Weiss \& Michael W. Klass eds., 1981)); see also Peirce \& Dworkin, supra note 128, at 679-80 ("[M]uch of the cost of industrial disease is not being made part of the cost of the product and passed on to the consumer. Instead, the burden of occupational disease is carried by the injured employee and public support systems such as social security and welfare. To the extent that occupational disease injuries escape the workers' compensation system, society at large pays for occupational disease through public programs rather than through market mechanisms."). 
employers may be able to externalize over ninety percent of the costs of risky behavior leading to deadly workplace diseases. ${ }^{132}$

The externalities in the context of workplace disease are significantly worse than the comparatively minor "leaks" in ex post compensation identified by Professor Lambert. And, as discussed above, the empirical evidence on wage differentials suggests that for workplace diseases like asbestosis, workers did not receive ex ante risk compensation. The negative externalities, combined with the information deficiencies that preclude employees from obtaining an efficient wage differential, "make the free market particularly ineffective in reducing occupational disease risks and compensating disease victims."133

\section{FAILuRE OF THE CURRENT REgulATORY REGIME}

As shown above, the free market does not drive employers to set efficient levels of risk and precaution for workplace disease. The consequences of this failure justify some form of regulatory intervention in the area. But what type of regulation is most likely to correct the market failure, set efficient levels of risk and precaution, and also adequately compensate injured employees? A narrowly tailored regulatory regime targeting the identified market failures will correct the inefficiencies yet avoid overly broad restrictions on the operation of the labor market. ${ }^{134}$ In this Part, I evaluate the status quo regulatory responses to the problem of workplace disease and demonstrate the ways in which they are ill-suited to correcting the market failures and meeting the dual goals of preventing unreasonable risks and compensating employees for the expected costs of occupational disease.

\section{A. State Workers' Compensation Statutes: A Breakdown of the Implicit Social Bargain in Chemical Exposure Cases}

In theory, state workers' compensation laws should correct the market failure by providing ex post compensation to injured workers and increasing the cost of risky behavior by employers. In practice, current state workers' compensation laws are terrible vehicles for allocating the expected costs of occupational diseases caused by chemical exposures. Workers' compensation laws often include a requirement that, to be compensable, an injury must be the result of an "accident." 135 As occupational diseases came to be recognized as a problem, a concern arose that an "accident" requirement would preclude recovery for illnesses caused by chronic exposures over time that were not the

${ }^{132}$ See Leigh \& Robbins, supra note 21, at 703; see also McCluskey, supra note 71 , at $775-76$.

133 Viscusi, supra note 4 , at 57-58.

${ }^{134}$ See Lambert, supra note 9, at 1008 ("Regulatory mismatch occurs when the government adopts a regulation that is too broad (or perhaps too narrow) to provide a tailored fit to the problem it is supposed to correct.").

135 Peirce \& Dworkin, supra note 128 , at 656. 
result of a single, identifiable accident. ${ }^{136}$ In recognition of this, many states adopted, either separately or as a component part of their workers' compensation laws, statutory provisions that relaxed the accident requirement and provided compensation for certain occupational diseases. ${ }^{137}$

The most common approach is a general one, in which the state workers' compensation statute includes "occupational disease" as a compensable injury, without identifying any specific diseases. In Missouri, for example, "occupational disease" is defined as:

[A]n identifiable disease arising with or without human fault out of and in the course of the employment. Ordinary diseases of life to which the general public is exposed outside of the employment shall not be compensable, except where the diseases follow as an incident of an occupational disease as defined in this section. 138

Occupational diseases are compensable under the Missouri statute "only if the occupational exposure was the prevailing factor in causing both the resulting medical condition and disability."139

States taking this generalized approach uniformly place the burden of proof on the claimant to establish that the disease falls under the coverage of the statute, although the articulation of this burden can vary. The West Virginia law illustrates a typical statement of the burden. There, a claimant bears the burden of proving:

(1) that there is a direct causal connection between the conditions under which [the] work is performed and the [] disease; (2) [the disease] can be seen to have followed as a natural incident ... of the employment; (3) [the disease] can be fairly traced to the employment as the proximate cause; (4) [the disease] does not come from a hazard to which [the employee] would have been equally exposed outside of the employment; (5) [the disease] is incidental to the character of the [employment] and not [outside] the ... employer/employee [relationship]; and (6) [the disease] appears to have had its origin in a risk connected [to] the employment ... ${ }^{140}$

Claimants in many states, including Arizona, ${ }^{141}$ Colorado, ${ }^{142}$ Georgia, ${ }^{143}$ Hawaii, ${ }^{144}$ Indiana, ${ }^{145}$ Iowa, ${ }^{146}$ Nevada, ${ }^{147}$ Oklahoma, ${ }^{148}$ South Carolina, ${ }^{149}$

${ }^{136}$ Id. at $656-58$.

${ }^{137}$ Id. at 659 ("In addition, several states scheduled diseases which were clearly occupationally related. If the disease was not scheduled, it was not compensated.").

${ }_{138}$ MO. AnN. STAT. $\$ 287.067 .1$ (West 2005 \& Supp. 2012).

${ }^{139}$ Id. $\$ 287.067 .2$.

140 W. VA. CODE ANN. $\$ 23-4-1$ (f) (LexisNexis 2010); see also Clark v. State Workmen's Comp. Comm'r, 187 S.E.2d 213, 216 (W. Va. 1972).

141 ARIZ. REV. STAT. ANN. $\$ \S 23-901(13)(\mathrm{c}), 23-901.01$ (2012); see also In re Estate of Bedwell, 104 Ariz. 443, 444 (1969).

142 COLO. Rev. StAt. \$ 8-40-201(14) (2011); see also Wal-Mart Stores, Inc. v. Indus. Claims Office, 989 P.2d 251, 252 (Colo. App. 1999). 
Tennessee, ${ }^{150}$ Virginia, ${ }^{151}$ and Wyoming ${ }^{152}$ must meet similarly onerous burdens to show that a disease is compensable under the applicable statute.

Arguably more forgiving statements of the claimant's burden are found in other states taking the general approach. For example, Montana requires that the claimant show "with a reasonable degree of medical certainty" that the disease was caused by the occupation. ${ }^{153}$ In Illinois, the claimant must show that it is "apparent to the rational mind... [that] a causal connection [exists] between the [work conditions] and the occupational disease."154 Claimants in Kentucky must establish that "[a] rational mind ... [can see] a causal connection between the conditions under which the work is performed and the occupational disease, and which can be seen to have followed as a natural incident" of the work exposure. ${ }^{155}$ In New Jersey, a claimant must prove that the disease is "due in a material degree" to conditions characteristic of the particular trade. ${ }^{156}$

Despite their minor variations, all these states place on the claimant the burden of proof on the critical question-whether a workplace exposure caused the disease. This allows a lack of scientific evidence on causation to inure to the benefit of employers, discourages the development of new toxicity information, and leads to excessive risk-taking and inadequate precautions by employers and chemical manufacturers.

A minority of states take a more targeted approach to occupational disease: one that might be referred to as a "disease scheduling" approach. Ultimately, this approach is no more effective in correcting the failure of the labor market than the generalized approach. New York is illustrative of the disease scheduling approach. New York's workers' compensation statute provides a

143 GA. CODE ANN. § 34-9-280(2) (2008).

144 HAW. REv. STAT. \$ 386-3(a) (West 2008); see also Flor v. Holguin, 9 P.3d 382, 39293 (Haw. 2000).

145 Ind. CODE ANN. $\$ 22-3-7-10$ (West 2005 \& Supp. 2012); see also SchwitzerCummins Co. v. Hacker, 112 N.E.2d 221, 230 (Ind. App. 1953).

146 IOWA CODE ANN. § 85A.8 (West 2009).

${ }^{147}$ NEV. REV. STAT. ANN. $\S \S 617.440,617.358$ (LexisNexis Supp. 2011).

148 OKLA. STAT. AnN. tit. 85, $\$ 308(33)$ (West 2012); see also Superior Stucco v. Daniels, 912 P.2d 317, 318 (Okla. 1995).

${ }^{149}$ S.C. CODE ANN. $\S \S 42-11-40,42-11-10$ (A) (Supp. 2011).

150 TENN. CODE ANN. \$§ 50-6-301, 50-6-303 (2008 \& Supp. 2011); see also Lyons v. Holston Def. Corp., 142 F. Supp. 848, 851 (E.D. Tenn. 1956).

151 VA. CoDE ANN. $\S \S 65.2-400,-403$ (2007); see also Blue Diamond Coal Co. v. Pannell, 122 S.E.2d 666, 669 (Va. 1961).

152 WyO. STAT. ANN. $\S \S 27-14-102(x i)(A), 27-14-603$ (a) (2011); see also Olson v. Fed. Am. Partners, 567 P.2d 710, 713 n.3 (Wyo. 1977).

153 MONT. CODE ANN. $§ 39-71-119(5)$ (2011); see also Schieno v. City of Billings, 683 P.2d 953, 955 (Mont. 1984).

154820 Ill. Comp. Stat. Ann. 310/1(d) (West 2011); see also Gross v. Ill. Workers'

Comp. Comm'n, 960 N.E.2d 587, 593 (Ill. App. Ct. 2011).

${ }_{155} \mathrm{~K}$. REV. STAT. ANN. $\$ 342.0011$ (3) (LexisNexis 2011).

156 N.J. StAT. ANN. § 34:15-31(a) (West 2011); see also Bayer v. Frank P. Farrell, Inc., 174 A.2d 221, 224 (N.J. Super. Ct. App. Div. 1961). 
schedule of specific compensable diseases and accompanying job processes. ${ }^{157}$ Employees have the right to compensation under the statute only if (with an exception discussed below) their "disability or death is caused by one of the diseases mentioned in [the schedule], and the disease is due to the nature of the corresponding employment as described in [the schedule]." 158 For instance, the New York schedule of diseases lists "[a]rsenic poisoning or its sequelae" corresponding to "[a]ny process involving the use of or direct contact with arsenic or its preparations or compounds." 159 Similar disease schedules are found in Idaho, ${ }^{160}$ Maryland, ${ }^{161}$ North Carolina, ${ }^{162}$ Pennsylvania, ${ }^{163}$ and Rhode Island. ${ }^{164}$

These disease scheduling schemes plainly operate only after it is too latetoo little precaution has already been taken in an industry, clusters of employees have developed diseases that can be causally connected to the job, and then a specific illness-occupation combination is added to the law. This is of no help in redressing the market failures that led employers to systematically take too much risk in the first place. Nor does it adjust either ex ante or ex post compensation for those employees who were injured prior to the scheduling of the illness-occupation pairing in the statute. Once there is sufficient, established evidence of a substance's toxicity (such as arsenic) to justify adding the pairing to the schedule, then the market may be capable of setting appropriate compensating wage differentials if the information can be effectively communicated to employees and potential employees. More importantly, employees will be able to successfully recover ex post compensation for such exposures under any workers' compensation scheme by proving causation with the well-established evidence on the toxic substance. Perhaps just as likely, the chemical at issue (or even the entire industry) will finally be deemed too dangerous to justify the compensating wages or workers' compensation costs, and its use will be discontinued. The diacetyl story illustrates the point. Any amendments to one of the disease scheduling statutes that adds the combination of "bronchiolitis obliterans/use of diacetyl" will come too late in the day to affect the prior inefficient risk/precaution behavior of diacetyl manufacturers and microwave popcorn producers. The microwave popcorn manufacturers have already moved on to the untested substitutes for diacetyl.

Recognizing this problem, states that follow the disease scheduling approach also include a "catch-all" provision in their worker disease statutes.

157 See N.Y. WORKERS' COMP. LAW $\S \S 3,47$ (McKinney Supp. 2012).

158 Id. \& 39.

${ }^{159}$ Id. $\$ 3.2$ no. 6 . A copy of the New York schedule of processes and occupational diseases located in $\S 3$ is reproduced herein at Appendix.

${ }^{160}$ IDAHO CODE ANN. \$ 72-438 (Supp. 2012).

161 Md. Code ANn., LAB. \& Empl. \$ 9-503 (LexisNexis Supp. 2011 ) (for limited public safety occupations, such as firefighters and police officers).

162 N.C. GEN. STAT. $\$ 97-53(2011)$.

16377 PA. CONS. STAT. ANN. $\S 1208$ (West 2002 \& Supp. 2012).

164 R.I. GEN. LAWS § 28-34-2 (2003 \& Supp. 2011). 
For example, the schedule in the New York statute contains this combination as entry number thirty on the schedule: "Any and all occupational diseases" corresponding to "[a]ny and all employments enumerated in subdivision one of section three of this chapter," which provides a list of "hazardous employments," broadly defined to include most jobs. ${ }^{165}$

Despite the seeming promise of such catch-alls, in practice they too fail to redress the information deficiency. Court interpretations of the catch-all provisions have imposed stringent requirements akin to those found in states taking the generalized approach. In New York, for example, the catch-all has been interpreted to apply only to diseases that arise from a particular, unusual aspect of the job. ${ }^{166}$ Thus, the catch-all provisions suffer from the same shortcomings as the provisions governing listed diseases. Identification of a disease-occupation combination comes too late to efficiently set risk/precaution levels.

A few jurisdictions employ some form of a presumption in favor of the claimant to shift the burden of production (but not the burden of persuasion) on causation. In Alaska, for example, the claimant obtains the benefit of this presumption after showing a "preliminary link" between the disability and his or her employment. ${ }^{167}$ To trigger the presumption, "the claimant need not present substantial evidence that his or her employment was a substantial cause of [the] disability."168 Once the preliminary link is established, "it is the employer's burden to overcome the presumption by coming forward with substantial evidence that the injury was not work related." 169 If the employer successfully rebuts the presumption in this manner, then the presumption "drops out and the employee must prove all the elements of the case by a preponderance of the evidence." 170

The Alaska Supreme Court has applied this presumption in cases involving occupational exposure to hazardous substances. In a case involving asthma allegedly caused by occupational exposure to sulfur dioxide and chlorine gas, the court found that the claimant had shown the required preliminary link by offering a physician's testimony that he believed the employee's "disease [was] secondary to airborne chemical burn ... perpetuated by continued exposure to sulfur dioxide and chlorine."171 The court held that the Alaska Workers" Compensation Board, in denying the employee's claim, had improperly

${ }^{165}$ N.Y. WORKERS' COMP. LAW $\$ 3.2$ no. 30 (McKinney Supp. 2012); see also infra Appendix.

166 See Goldberg v. 954 Marcy Corp., 12 N.E.2d 311, 313 (N.Y. 1938).

${ }^{167}$ La. Pac. Corp. v. Koons, 816 P.2d 1379, 1381 (Alaska 1991) (quoting Cheeks v. Wismer \& Becker, 742 P.2d 239, 243-44 (Alaska 1987)); see also ALASKA STAT. $\S 23.30 .120(\mathrm{a})(1)(2010)$.

168 Koons, 816 P.2d at 1381 (alterations in original) (quoting Cheeks, 742 P.2d at 24344).

${ }^{169} \mathrm{Id}$. (quoting Burgess Constr. Co. v. Smallwood, 698 P.2d 1206, 1211 (Alaska 1985)).

170 Id.

${ }^{171} I d$. (alteration in original). 
required the claimant to establish that his asthma was work-related, rather than requiring the employer to overcome the presumption by showing that the asthma was not caused by his employment. ${ }^{172}$

The District of Columbia workers' compensation statute contains a similar presumption, but it is less clear how that presumption would be applied in cases involving exposures to hazardous chemicals. ${ }^{173}$ The small minority of jurisdictions employing a presumption in favor of the claimant may be more effective at responding to the market failure, but they are not complete solutions, as I demonstrate below in Part VI. In any event, they are overshadowed by the vast majority of U.S. jurisdictions that place the burden of proving disease causation squarely on the claimant.

Aside from their inability to adjust the risk/precaution behavior of chemical manufacturers and employers, current state worker disease laws also fail to meet the second goal of workers' compensation programs: providing adequate compensation for victims without imposing prohibitive litigation costs. The implicit social bargain justifying workers' compensation schemes is that employers will benefit from defined and limited liability, while employees will benefit from quick adjudication without requiring the employee to establish negligence. ${ }^{174}$ But this supposed social bargain does little or no good for workplace disease victims. Relieving employees of the burden of proving negligence is of little comfort when they still bear the burden of establishing that an exposure directly caused or contributed to a disease-the precise issue on which scientific evidence usually is lacking, or at least is vigorously disputed by the employer. Indeed, the legal conclusion that an employer was negligent would often follow directly if there were substantial scientific evidence showing that exposure to a particular chemical at certain levels directly caused or contributed to the disease in question. ${ }^{175}$ Quick, cheap adjudications are an unfulfilled promise in the realm of worker disease, precisely because of the lack

172 Id. at 1382 .

173 D.C. CODE $\$ 32-1510$ (LexisNexis Supp. 2012); see also Georgetown Univ. v. D.C. Dep't of Emp't Servs., 971 A.2d 909, 916 (D.C. 2009) (occupational diseases are "injuries" under the statute, which contains a statutory presumption of compensability, if they "arise out of and in the natural course of employment").

174 See, e.g., McCluskey, supra note 71, at 670.

175 Compare this proof problem to the quintessential workplace accidental injury case, in which an employee loses a limb while operating industrial machinery. There, the causal connection between the work and the harm is not in doubt - the operation of the machine obviously led to the loss of limb. But the question of whether the employer was negligent could be complicated and difficult to resolve. The employer may have taken all reasonable precautions to ensure the safety of the machine. The tort doctrines of contributory or comparative negligence or assumption of risk might apply if the employee removed a safety device, operated the machine while impaired, or was simply inattentive. The implicit social bargain of workers' compensation removes these roadblocks to recovery for employees. 
of available scientific causation information. Worker disease claims are disputed three times more often than ordinary injury claims. ${ }^{176}$

Although employees get little or no benefit from the supposed social bargain, workers' compensation statutes still limit the recovery available to employees and bar tort claims based on workplace exposures. For example, in most states, the workers' compensation law provides that employees may not recover for nondisabling pain and suffering. ${ }^{177}$ Further, this limited workers' compensation remedy is the employee's exclusive remedy against the employer, unless the worker can fit within the intentional tort exception. ${ }^{178}$ To fit within the intentional tort exception, the employee must establish "an intentional or deliberate act by the employer directed at causing harm to this particular employee."179 Of course, this standard is virtually impossible to meet where there is little evidence on the toxicity of a chemical or substance. How could an employer have intended to harm the employee by exposing her to a chemical when the science on the chemical is murky? The result is that a worker suffering from workplace disease bears all the burdens imposed by the implicit social bargain of the workers' compensation system, including the inability to bring a tort claim against his employer and statutory damage limitations, but he gets none of the supposed benefits of that social bargain.

\section{B. The Tort System Fails as an Alternative Source of Ex Post Compensation}

As the diacetyl story illustrates, workers sometimes look for an alternative source of ex post compensation for occupational disease by suing chemical manufacturers in tort. ${ }^{180}$ Although some microwave popcorn workers successfully obtained jury verdicts or settlements, this was due in large part to the unique characteristics of bronchiolitis obliterans. For most workplace

176 See also McCluskey, supra note 71 , at 776 (noting that causation disputes and other issues lead employers to challenge disease claims at higher rates than worker injury claims, and citing an earlier study finding that employers contest disease claims at six times the rate of other work injury claims).

177 See Joseph H. King, Jr., Pain and Suffering, Noneconomic Damages, and the Goals of Tort Law, 57 SMU L. REV. 163, 204 n.247 (2004) (citing 1 ARTHUR LARSON \& LEX K. LARSON, WORKERS' COMPENSATION LAW $\S 1.03$ [4] (2003)); McCluskey, supra note 71, at 809; Viscusi, supra note 4, at 62.

178 See, e.g., N.Y. Workers' Comp. LAw $\$ 11$ (McKinney Supp. 2012); Mylroie v. GAF Corp., 81 A.D.2d 994, 995 (N.Y. App. Div. 1981); see also McCluskey, supra note 71, at 809; Viscusi, supra note 4, at 68.

179 Mylroie, 81 A.D.2d at 995.

180 Viscusi, supra note 4, at 65 ("Over the past decade, however, disease victims have attempted to circumvent the restrictions of workers' compensation programs by bringing products liability claims against the manufacturers of hazardous materials used in the workplace."). 
diseases, the tort system is generally thought to be ill-equipped to resolve such claims, as several commentators have recognized. ${ }^{181}$

The tort system does not cure the information problem, but rather exacerbates it. Whether suing in strict liability or negligence, courts still require the plaintiff to prove that exposure to the chemical in question proximately caused the plaintiff's illness. ${ }^{182}$ Manufacturers still have an incentive to avoid developing new information. This ignorance incentive is enhanced by other features of the tort system. Under a strict liability defective product theory, for example, a worker will often be required to show that a chemical product was "unreasonably dangerous." 183 This will typically require a showing of both toxicity and precaution cost information. Even under a strict liability failure-towarn theory, the worker will be required to establish that the manufacturer failed to warn of a "particular risk" which was "known or knowable in light of the generally recognized and prevailing best scientific and medical knowledge available at the time."184 Additionally, statutes of limitation and long latency periods will impede tort recovery. ${ }^{185}$ Given the proof required to succeed even under strict liability claims, chemical manufacturers have strong incentives to avoid the development of new scientific information.

The tort system does not correct the labor market failure and will not lead to efficient allocations of risk and precaution on employee exposures for several reasons identified by Professor Viscusi: information deficiencies, high transaction costs impeding settlements, insurance pooling that allows manufacturers to spread the risk of large judgments and thereby dilute

181 See, e.g., Lin, supra note 1, at 966 (arguing that the tort system "discourages manufacturers from producing toxicity information, encourages manufacturers to hinder third-party efforts to develop such information, and renders effective enforcement of the duty to test impossible"); Viscusi, supra note 4, at 66 (arguing that "tort suits provide a poor mechanism for promoting efficient levels of health risk").

182 Viscusi, supra note 4, at 66; see also Lin, supra note 1, at 960-61 ("In reality, however, environmental toxic tort plaintiffs are frustrated by gaps in knowledge regarding causation, risk, and harm. Often the most significant of these obstacles is causation. Toxicity testing has the potential to generate information on the ability of a chemical to cause illness, but the lack of such testing often prevents plaintiffs from establishing a prima facie case. Even when the available data is sufficient to support a regulatory response, it is usually insufficient to support a finding of causation in an individual tort case." (footnotes omitted)).

183 RESTATEMENT (SECOND) OF TORTS $\$ 402 \mathrm{~A}$ (1965); Viscusi, supra note 4, at 66 ; see also RestATEMENT (THIRD) OF TORTS: PRODUCTS LIABILITY $§$ 2(b) (1998) (defining a design defect as "when the foreseeable risks of harm posed by the product could have been reduced or avoided by the adoption of a reasonable alternative design by the seller or other distributor, or a predecessor in the commercial chain of distribution, and the omission of the alternative design renders the product not reasonably safe").

${ }^{184}$ Anderson v. Owens-Corning Fiberglass Corp., 810 P.2d 549, 558 (Cal. 1991) (construing "comment $\mathrm{j}$ " of section 402A of the Restatement (Second) of Torts); see also Restatement (Third) of Torts: Products Liability $§ 2(\mathrm{c})$ (1998); Restatement (SECOND) OF TORTS $\S 388$ (1965) (negligent failure to warn); Viscusi, supra note 4, at 66.

185 Viscusi, supra note 4 , at 68 . 
incentives, and because the tort awards come many years after exposure, preventing efficient incentive feedback to risk/precaution behavior. ${ }^{186}$

\section{OSHA Exposure Limits}

Neither workers' compensation nor tort law corrects the market failures described above. The OSH Act and OSHA regulations were intended to fill the gap by setting minimum floors for worker safety, but they have not been up to the task. OSHA's command and control regulations have been persistently criticized from all sides since the OSH Act was enacted in $1970 .{ }^{187}$ Economists criticize them as unnecessarily preventing gains from trade. ${ }^{188}$ Other scholars criticize the high burdens placed on OSHA for supporting and justifying any command and control standards it seeks to impose on employers. The Supreme Court requires that before OSHA may promulgate a permanent health or safety standard, it must first make a threshold finding that a "significant risk" is present that can be eliminated or reduced by a change in practices. ${ }^{189}$ Proposed standards for exposures to toxic materials must also be shown to be feasible. ${ }^{190}$ Additionally, OSHA is not permitted to presume that there is no safe exposure level for a carcinogenic substance in the absence of specific dose-response

${ }^{186}$ See id. at 69-70. Professor Viscusi concludes: "In short, products liability law strives both to compensate disease victims and deter workplace health risks. The inability of the products liability system to achieve either goal suggests that the objectives of compensation and reduced health risk must be addressed separately if both are to be achieved." Id. at 70 .

${ }^{187}$ See, e.g., Bisom-Rapp, supra note 51, at 1208-09 (describing historical criticism from academics, business interests, and organized labor).

188 See Lambert, supra note 9, at 1010.

189 Indus. Union Dep't v. Am. Petroleum Inst., 448 U.S. 607, 639-42 (1980) (plurality opinion) (construing sections $3(8)$ and $6(\mathrm{~b})(5)$ of the OSH Act, codified at 29 U.S.C. $\S \S 652(8)$ and $655($ b) $(5)$, respectively) (sometimes referred to as the "Benzene Case"). In determining whether a "significant risk" is present, OSHA often looks to a passage from the plurality opinion by Justice Stevens in Industrial Union suggesting that a lifetime risk of dying of cancer from a given exposure of one in one billion is insignificant, while a lifetime risk of fatality of one in one thousand from a regular exposure is significant, and will justify steps to decrease or eliminate the risk. Id at a55; see also Cass R. Sunstein, Is OSHA Unconstitutional?, 94 VA. L. REV. 1407, 1426-27 (2008).

${ }^{190}$ Occupational Safety and Health Act, 29 U.S.C. $§ 655(b)(5)(2006)$ ("The Secretary, in promulgating standards dealing with toxic materials or harmful physical agents under this subsection, shall set the standard which most adequately assures, to the extent feasible, on the basis of the best available evidence, that no employee will suffer material impairment of health or functional capacity even if such employee has regular exposure to the hazard dealt with by such standard for the period of his working life.... In addition to the attainment of the highest degree of health and safety protection for the employee, other considerations shall be the latest available scientific data in the field, the feasibility of the standards, and experience gained under this and other health and safety laws." (emphasis added)). 
data. ${ }^{191}$ Instead, it must make findings of health effects at low exposure levels in order to justify setting PEL's at such low levels. ${ }^{192}$

These burdens, combined with OSHA's limited resources for developing and evaluating scientific information, have effectively prevented OSHA from implementing permanent standards for workplace exposures for thousands of potentially hazardous chemicals. ${ }^{193}$ Due at least in part to the heavy burdens on OSHA to meet the significant risk and feasibility hurdles and defend new standards against challenges, the pace of new OSHA permanent PEL standards has been glacial. ${ }^{194}$ Compounding the problem, even where PEL standards are in place, OSHA's enforcement of standards is generally viewed as inept. ${ }^{195}$ OSHA inspections are relatively rare and fines for infractions are comparatively miniscule. ${ }^{196}$

A more fundamental problem with relying on OSHA command and control regulations to correct the market failures is that OSHA is not the least-cost provider of chemical toxicity information, information on the costs of replacing a chemical, or information on the feasibility of instituting other precautions. ${ }^{197}$ This information is required to meet the significant risk and feasibility burdens set by the Court for new standards. ${ }^{198}$ OSHA is not in a position to promulgate standards for the thousands of high volume chemicals in the United States for

191 Indus. Union, 448 U.S. at 659.

192 Id.; see also MiCHAELS, supra note 51, at 32 ("From the start, however, OSHA recognized that centralized standard setting and top-down enforcement of regulations would never be sufficient. In a world with thousands of toxic chemicals, the agency could never set workplace regulations for all of them, nor could it ever have enough inspectors to visit every workplace on any sort of regular basis.").

193 See MiCHAELS, supra note 51, at 120 ("Because OSHA has been so beaten down by the opponents of regulation, it has virtually given up on developing new regulations or strengthening outdated ones."); see also CrAIG COLLINS, TOXIC LOOPHOLES 115 (2010) ("While the [National Toxicology Program] busies itself studying the cancer effects of a few dozen chemicals, about 1,000 new compounds flood commercial markets. Fully evaluating the dangers of 1,000 new chemicals every year, especially in combination with the 70,000 already in use, is far beyond the budget of the EPA or any other governmental body.").

194 See, e.g., MiChAELS, supra note 51, at 32 (noting that the Industrial Union decision "handcuffed the agency because establishing each new standard would now take years and thousands of staff-hours to produce"); McGarity, supra note 9, at 101 ("[A] consensus is rapidly emerging that the regulatory regime created by the OSH Act is broken and badly in need of repair.... During the last twelve years OSHA has promulgated a pitifully small number of occupational health standards and not a significantly larger number of occupational safety standards.").

195 Bisom-Rapp, supra note 51, at 1209-11.

${ }^{196}$ Id.

${ }^{197}$ See generally Richard J. Butler \& John D. Worrall, Wage and Injury Response to Shifts in Workplace Liability, 61 InDus. \& LAB. REL. REV. 181, 182 (2008) ("Even where bargaining is prohibitively expensive, the Coase analysis of liability has implications for optimal safety outcomes. Efficient safety can be achieved by assigning the liability to the least-cost avoider.").

198 Indus. Union Dep't v. Am. Petroleum Inst., 448 U.S. 607, 639-42 (1980). 
which no toxicity data is available, let alone the tens of thousands of chemicals used in lesser quantities. ${ }^{199}$ OSHA does not have the resources to design and conduct animal studies or to explore and study possible naturally occurring experiments that could provide epidemiological information sufficient to perform risk assessments or PEL standard feasibility analyses on each of these chemicals. Asking OSHA to fill the information void with command and control regulations setting exposure limits is not realistic and does not address the underlying information deficiency. ${ }^{200}$

\section{OSHA Information Communication Standards}

Recognizing the difficulties of gathering the data needed to set PELs for individual chemicals, as well as the potential benefits of requiring the disclosure of what little information does exist, OSHA in 1983 promulgated the Hazard Communication Standard. ${ }^{201}$ This standard requires chemical manufacturers to provide MSDS to their customers for any chemicals posing a "health hazard," defined as any chemicals "for which there is statistically significant evidence based on at least one study conducted in accordance with established scientific principles that acute or chronic health effects may occur in exposed employees."202 The Hazard Communication Standard also requires chemical manufacturers to update their MSDS with any new or significant information within three months of learning such information. ${ }^{203}$ Employers are then required to make the MSDS available to their employees. ${ }^{204}$

If employees were the only ones operating in the dark about chemical toxicity risks, then regulations requiring employers to disclose such information would be an appropriate and perhaps sufficient solution. ${ }^{205}$ Information

${ }^{199}$ See Lin, supra note 1, at 958-59 (“A 1998 Environmental Protection Agency (EPA) study of toxicity data on high production volume (HPV) chemicals - those three thousand or so chemicals imported or produced in the United States in a volume of over one million pounds per year - found no toxicity information publicly available for nearly half of the chemicals identified. For only a handful of these chemicals—seven percent-was a full set of basic toxicity information available. While voluntary efforts in the last decade have sought to collect or generate more information on the potential toxic effects of HPV chemicals, significant information gaps remain. Toxicity data is even more lacking for the 80,000 or so non-HPV chemicals found in commerce today." (footnotes omitted)).

${ }^{200} \mathrm{Id}$. at 960 ("The absence of toxicity data hampers these agencies' [including OSHA's] ability to carry out basic regulatory tasks such as conducting risk assessments, developing safety guidelines, setting regulatory standards, defending regulations from legal challenges, and warning the public about potential hazards.").

20129 C.F.R. $\$ 1910.1200$ (a)(1) (2011); see also MiCHAELS, supra note 51, at 32 (noting that the chemical industry pushed OSHA to issue the hazard communication standard in an effort to avoid the problem of complying with disparate state and local right-to-know laws).

20229 C.F.R. $\S 1910.1200$ (c) (2011).

${ }^{203} \mathrm{Id}$. $1910.1200(\mathrm{~g})(5)$.

${ }^{204}$ Id. $\$ 1910.1200(\mathrm{~g})(8)$.

205 See Lambert, supra note 9, at 1030-32. 
disclosure regulations directing employers to provide safety and risk information to employees — or as Professor Lambert suggests, to a centralized information clearinghouse-would be narrowly tailored to the problem while permitting the market to encourage efficient wage/risk transactions. ${ }^{206}$

The problem for chemical exposure risks is that the information gap goes much deeper. As Professor Lambert acknowledges, mandatory information disclosure regulations cannot prevent market failure where employers themselves lack information. ${ }^{207}$ If employers do not have adequate information on the risks of exposures to a given chemical or substance, then requiring them to provide the information in their possession accomplishes nothing. The diacetyl story is illustrative. In the 1990s, many MSDSs for diacetyl provided little information about potential serious respiratory health effects due to chronic inhalation exposures, despite the existence of the unpublished 1993 BASF study. ${ }^{208}$ At the time, the study conducted by BASF was not available to other diacetyl manufacturers, microwave popcorn manufacturers, or to the public. 209 Even today, years later and after several "popcorn lung" lawsuits, many current diacetyl MSDSs do not contain adequate information about potential serious respiratory effects. ${ }^{210}$

Chemical manufacturers are more likely to possess some risk information, justifying the Hazard Communication Standard's requirement that manufacturers provide health hazard guidance to employers. If chemical manufacturers actually conducted adequate toxicity testing on all of their chemicals and then fully and accurately reported the results on MSDS, then the Hazard Communication Standard might be effective. In practice, however, the disincentives to test chemicals and generate information further thwart the goals of the Hazard Communication Standard.211 The chemical dispersant Corexit 9500 , used in the response to the Deepwater Horizon oil spill, is an excellent

${ }^{206}$ Id. at 1048-49 (advocating a mandatory disclosure regime requiring the disclosure of information by the employer to employees, or alternatively to a central clearinghouse for access by employees, where "the market failure at issue is systematic employee ignorance of risks and there is no reason to believe that employers are systematically under-informed of available safety precautions").

207 Id. at 1049.

${ }^{208}$ See Firmenich Incorporated's Statement of Material Facts Not in Dispute in Support of Motion for Summary Judgment on Count III of Plaintiff's Complaint at paras. 4 5, Blood v. Givaudan Flavors Corp., No. 07-CV-00142-MWB (N.D. Iowa Apr. 17, 2009) (citing Exhibit J, a Firmenich MSDS dated Aug. 27, 1999, at 44 45, that provides no information about any scientific health studies, and indicates that "[t]he identity of individual components of this mixture is proprietary information and is regarded to be a trade secret," that "[v]apor may be irritant to eyes, nose, throat and respiratory tract," and that "[p]rolonged inhalation at high levels may cause serious health effects"); see also supra note 27 and accompanying text.

${ }^{209}$ See supra notes $27-29$ and accompanying text.

210 OSHA Diacetyl Hazard Communication, supra note 48.

211 See MCGARITY \& WAGNER, supra note 68, at 117, 119. 
example of the ineptitude of the Hazard Communication Standard. ${ }^{212}$ Although thousands of gallons of Corexit 9500 were used, and employees claimed they were exposed to the chemical during the response efforts, the MSDS for Corexit 9500 provides only this information on toxicity: "No toxicity studies have been conducted on this product." 213 Likewise, the MSDS for the suspected diacetyl substitute 2,3-pentanedione provides: "To the best of our knowledge, the chemical/physical/toxicological properties have not been thoroughly investigated."214

The Hazard Communication Standard also contains a loophole, in that it permits chemical manufacturers to withhold the specific chemical identities for mixtures or substances if the manufacturer can support a claim that the mixture or substance is a trade secret. ${ }^{215}$ In the diacetyl story, the chemical components of the diacetyl substitutes are not known to the public nor required to be disclosed on an MSDS because of assertions of trade secret protections. ${ }^{216}$

The Hazard Communication Standard has proven incapable of overcoming the economic incentives for chemical manufacturers and employers to avoid the development and dissemination of toxicity information on the chemical products they sell or use in their workplaces. ${ }^{217}$ Even assuming that sufficient toxicity data were developed and provided in an MSDS, behavioral economists have raised legitimate questions about employees' ability to understand and adequately process this risk-based information. ${ }^{218}$ If employees cannot understand the risk information contained in an MSDS, then the labor market will be unable to set an appropriate compensating wage differential for riskier jobs. Finally, the Hazard Communication Standard, by itself, does nothing to address the negative externalities identified in Part III.B. Requiring the communication of the latest scientific risk information is not the same as requiring the development of new scientific information. Without new scientific information, the current burden allocation scheme prevents proper ex post compensation for injuries due to questions of causation, long latency periods, and potential contributing factors.

\section{E. OSHA Voluntary Compliance and Cooperative Programs}

One final component of the current regulatory regime merits consideration. Based largely on principles of deregulation and "new governance," and motivated in part by the difficulty OSHA faces in adopting permanent standards, OSHA recently began to emphasize voluntary compliance programs.

212 See supra note 93 and accompanying text.

213 See NALCO, supra note 100 , at 5-6.

214 LANSDOWNE AROMATICS, supra note 62, at 2.

215 OSHA Hazard Communication, 29 C.F.R. $\$ 1910.1200$ (2011).

216 See supra note 66 and accompanying text.

${ }^{217}$ Frances L. Edwards, Worker Right-to-Know Laws: Ineffectiveness of Current PolicyMaking and a Proposed Legislative Solution, 15 B.C. ENVTL. AFF. L. REV. 1, 18-28 (1987).

${ }^{218}$ See id. at $19-20$. 
A voluntary compliance approach involves the exchange of risk and precaution information among OSHA, employers, worker advocates, and other stakeholders, and an effort by OSHA to convince employers to voluntarily comply with suggested or recommended guidelines based on such information. 219

A voluntary compliance scheme is a particularly poor regulatory fit for chemical exposure hazards. First, OSHA typically lacks the information necessary to suggest guidelines for the vast majority of the thousands of untested chemicals in commerce. Thus, it is not clear what specific recommendations OSHA can offer. Second, a voluntary compliance program does nothing to address the negative externalities outlined in Part III.B. If employers can effectively pass the expected costs of risky chemical exposures off onto workers, their families, health insurance programs, and social security programs, then they will have no incentive to take costly precautions to meet voluntary unenforced guidelines. Without altering the incentives of employers and chemical manufacturers, voluntary programs will do no good. ${ }^{220}$ Employers and chemical manufacturers will always be motivated by their economic interests, and if it is in their economic interests to remain ignorant of chemical risks and externalize costs of illness, they will do so.

The ineffectiveness of voluntary compliance or cooperative programs with respect to chemical exposures is vividly demonstrated by two examples. First, consider OSHA's response to the diacetyl concerns raised in Missouri. OSHA entered into a voluntary partnership agreement with a group of microwave popcorn manufacturers in 2002.221 The stated goal was for industry and OSHA to work together to develop a Hazard Information Bulletin that would serve to transmit risk information to employees. ${ }^{222}$ But the agreement failed and no

${ }^{219}$ On voluntary compliance programs and new governance, see generally Bisom-Rapp, supra note 51; Cynthia Estlund, Something Old, Something New: Governing the Workplace by Contract Again, 28 COMP. LAB. L. \& POL'Y J. 351 (2007); Orly Lobel, Setting the Agenda for New Governance Research, 89 MINN. L. REV. 498 (2004); Orly Lobel, The Renew Deal: The Fall of Regulation and the Rise of Governance in Contemporary Legal Thought, 89 MinN. L. Rev. 342 (2004); Douglas Nejaime, When New Governance Fails, 70 OHIO St. L.J. $323(2009)$.

220 See MTCHAELS, supra note 51, at 115-16 ("Bluntly put, OSHA has moved from a regulatory to a collaborative/consultative model. By design, these agreements 'do not include an enforcement component.' ... It is only a slight exaggeration to say that these alliances are little more than a way for the agency to look busy." (quoting OSHA Fact Sheet: OSHA Alliance Program, OCCUPATIONAl SAFETy \& HEAlth Admin., http://www.osha.gov/ OshDoc/data_General_Facts/factsheet-alliance.pdf (last visited Sep. 28, 2012))). Although not as pessimistic about cooperative programs as Michaels, Professor Bisom-Rapp nonetheless acknowledges that "during times of deregulation, the regulatory agencies in which such innovative [new governance] programs are housed may well be inclined to render the programming cosmetic rather than substantive." Bisom-Rapp, supra note 51, at 1264.

221 See supra note 36 and accompanying text.

222 See Dulberg, supra note 25, at 98. 
Hazard Information Bulletin materialized from the partnership. ${ }^{223}$ The explanation is simple: industry did not have sufficient information about the risks of diacetyl and had a disincentive to develop that information. Insufficient information on diacetyl continues to prevent the communication of risk to employees, and the process of gathering information for the potential development of a permanent exposure standard for diacetyl has just begun. ${ }^{224}$ It should be obvious that voluntary compliance programs do no good where the main difficulty is insufficient information to develop an agreed-upon standard, guideline, or suggested voluntary benchmark for employers to meet.

A second example involves a voluntary compliance program developed by the Environmental Protection Agency (EPA) to address the persistent lack of toxicity testing on chemicals in commerce. In 1998, the EPA entered into a voluntary initiative called the High Production Volume Challenge Program, in which some chemical companies agreed to make basic toxicity information for certain high volume chemicals available to the public by 2004.225 As of 2007 , toxicity data was offered for only about half of the sponsored chemicals. ${ }^{226}$ Most of the new information consisted only of unpublished prior studies or different risk and toxicity analyses applied to data that had already been generated in older studies. ${ }^{227}$ New testing was done on only a small fraction of the sponsored chemicals. ${ }^{228}$ This lackluster effort by the chemical industry should not be surprising. The voluntary compliance program did not alter the economic disincentives for chemical manufacturers to conduct new testing.

As shown by the diacetyl story and the High Production Volume Challenge, voluntary compliance and cooperative programs do not fundamentally change economic incentives and therefore hold little promise for solving the workplace disease problem.

\section{PRIOR PROPOSALS FOR REFORM}

Recognizing the market and regulatory failures, other scholars have offered a number of proposed solutions rooted in changes to environmental law, employment law, tort law, or even social security law. These proposals range from entirely replacing command and control OSHA regulations with more limited, information-focused optional regulations, ${ }^{229}$ to adopting a Superfund-

223 Id.

224 See supra note 49 and accompanying text.

225 Lin, supra note 1, at 970-71.

${ }^{226}$ See id. at 971 .

227 Id.

228 See id.

${ }^{229}$ See Lambert, supra note 9, at 1011-12 (advocating a more limited regulatory scheme, which would generally replace command and control OSHA regulations with information disclosure regulations). 
style statute funding independent government research on chemical toxicity, ${ }^{230}$ to enacting comprehensive federally funded compensation programs using the social security framework (paid for by risk-based taxes on employers), ${ }^{231}$ to using public nuisance tort law to obtain injunctive relief mandating chemical testing. ${ }^{232}$ In recent years, the search for a solution has turned to the possibility of replicating the European Union's (EU) new system of pre-market registration and authorization of chemicals, known as the Registration, Evaluation, Authorization and Restriction of Chemicals (REACH) program. ${ }^{233}$

Although I do not attempt to catalogue and evaluate every proposal advanced by other writers, below I explore several of the leading proposals and identify key shortcomings of each. The two most common deficiencies of the proposals to date are that they: (1) fail to adequately capitalize on the financial incentives of employers and chemical manufacturers, leaving open the possibility for continued externalization of the expected costs of exposure; or (2) fail to adequately compensate employees actually injured by workplace exposures to hazardous chemicals.

\section{A. The Superfund Model for Funding Independent Government Research}

An early proposal by Professor Lyndon, loosely modeled after the Comprehensive Environmental Response, Compensation, and Liability Act (CERCLA), commonly known as Superfund, suggested the creation of a general fund to sponsor the study of chemical toxicity. ${ }^{234}$ The general fund would be supported by a tax on the petrochemical industry. 235 This "super study" program would pay for both public and private institutions to conduct research on toxicity and exposure to chemicals according to a general, national plan. If this research demonstrates that a chemical is harmful, then custodians of the fund would be permitted to bring a reimbursement action against the manufacturers. Liability would be joint and several, with apportionment according to human exposure rates. ${ }^{236}$

The primary strength of this proposal is that it would alleviate concerns about biased study results stemming from conflicts of interest potentially created by industry-sponsored research. There are drawbacks, however. One political drawback is demonstrated by the current Superfund situation. In 1995,

${ }^{230}$ See Mary L. Lyndon, Information Economics and Chemical Toxicity: Designing Laws to Produce and Use Data, 87 MiCH. L. REv. 1795, 1836-37 (1989).

231 See Viscusi, supra note 4, at 56-57.

232 See Lin, supra note 1, at $990-91$.

${ }^{233}$ See David E. Adelman, A Cautiously Pessimistic Appraisal of Trends in Toxics Regulation, 32 WASH. U. J.L.\& POL'Y 377, 378 (2010) (calling REACH the "brightest light in the firmament" of toxics regulation).

234 See Lyndon, supra note 230, at 1835-41.

235 See id. at 1836.

236 See id. at 1837. 
Congress refused to renew the special tax that financed the Superfund. ${ }^{237}$ Since then, hazardous waste site cleanups have declined, and the cleanup of "orphaned" sites (where there are no identifiable potentially responsible parties with assets to pay for the cleanup) are now effectively paid by the general taxpaying public, not by chemical manufacturers or industry. ${ }^{238}$ Even assuming that Professor Lyndon's super study legislation could get off the ground in the current political climate, it would likely have the same political vulnerabilities as the Superfund. A later Congress may refuse to renew the tax on the petrochemical industry, leaving the general taxpaying population to fund toxicity research while chemical manufacturers and employers continue to externalize the majority of expected costs of risk from chemical exposures.

Aside from political concerns, some theoretical drawbacks suggest that a super study program would be misguided. First, the government is not the leastcost information provider. Manufacturers of chemicals tend to be in the best position to test them, because they know the most about the chemical structure of their compounds and they have a better sense of which ones are likely to pose risks to the environment or to human health. This is reflected in prior instances where manufacturers had indicators of problems before the public or government regulators. ${ }^{239}$ The chemical industry is best situated to prioritize chemical compounds for study. The super-study, government-led research would therefore be more difficult and more costly than industry-directed research. ${ }^{240}$

Finally, it is not clear how the super study program would affect the compensation goal of the worker safety regime, if at all. Under Professor Lyndon's proposal, the general fund supporting the studies would be replenished by reimbursement actions against the manufacturers of chemicals found to be harmful after testing. ${ }^{241}$ But the reimbursement payments to the fund would do nothing to compensate workers who had previously been exposed to the chemicals in question, but were not able to recover for their illnesses for years (or possibly never, if the applicable workers' compensation limitations period would bar their claims). ${ }^{242}$ If the level of combined ex ante and ex post compensation for risky behavior does not rise to cover all the true costs of such behavior, then the proposed reform will fail to achieve an efficient allocation of risk and precaution. The super study would, at best, provide an incremental adjustment to the risk/precaution behavior of chemical manufacturers and employers.

${ }^{237}$ See John M. Broder, Without Superfund Tax, Stimulus Aids Cleanups, N.Y. TImES, Apr. 26, 2009, at 16 .

238 See id.

${ }^{239}$ See, e.g., supra notes $27-29$ and accompanying text (discussing the early BASF animal study of diacetyl).

240 See Lin, supra note 1, at 997.

241 See Lyndon, supra note 230, at 1835-41.

${ }^{242}$ See supra note 129 and accompanying text. 


\section{B. Opt-Out OSHA Standards}

Professor Lambert contends that where information deficiencies are facing not just employees, but also employers, the best regulatory fit is an opt-out OSHA standard. ${ }^{243}$ Professor Lambert offers ergonomic standards as one example of situations in which an employer may have difficulty generating or evaluating information about safety risks and available precautions and their costs. Under Professor Lambert's approach, OSHA would adopt an optional standard and provide employers with information about safety risks. Employers would be obligated to meet the standard unless they opted-out by providing safety risk information to employees and explaining to employees the reasons why following the standard would be inappropriate or uneconomical for that particular employer. ${ }^{244}$ Opt-out regulations, according to Professor Lambert, are narrowly suited to resolving informational market failures while still permitting gains from trade in cases where compliance with a standard would prove more costly than paying wage differentials (combined with expected ex post compensation) to risk-preferring employees. ${ }^{245}$

Opt-out regulations may hold at least some promise where information problems are facing employees and employers, but not regulators. OSHA may be in a position to cheaply research or collect risk information and develop optout standards for workplace risks such as ergonomics, where researching costeffective precautionary measures may not be as expensive as chemical toxicity testing and where assertions of trade secrets are unlikely to block study. ${ }^{246}$ But for chemical exposures, where severe information obstacles are facing not just employees and employers, but also the regulators themselves, opt-out regulations will not cure the market failures.

${ }^{243}$ Lambert, supra note 9, at 1070 ("An opt-out regulation would specify a particular cost-effective precaution an employer must take unless she opts out of complying with the rule by notifying her current and prospective employees of (1) the hazard the precaution would address, (2) the nature of the precaution at issue and the fact that the government has recommended it, and (3) the fact that she is opting out of compliance with the rule."). One potential difficulty with this approach, in general, is that current employees may not be in a position to negotiate an adequate compensating wage differential when an employer opts out, because of the investments that current employees have made in selecting this job. Such investments may include, for example, foregoing other employment offers that are now expired, and relocating family. See Lyndon, supra note 230, at 1834 ("Workers are particularly vulnerable with respect to occupational health risks. Geographic and economic factors limit their discretion to choose among risks."). Older employees may also have difficulty finding new alternative employment if they are unsatisfied with the employer's offered wage differential. See generally Stewart J. Schwab, Life-Cycle Justice: Accommodating Just Cause and Employment at Will, 92 MICH. L. REV. 8 (1993).

244 See Lambert, supra note 9, at 1070-71.

245 See id. at 1049-50.

${ }^{246}$ See id. at 1068 (providing as an example OSHA's voluntary ergonomics guidelines for the meat-packing industry, which amount to advice to the industry regarding potential cost-saving precautionary measures). 
Initially, for reasons discussed above, employees will be unlikely to correctly process any chemical risk information the employer provides and, in any event, unable to negotiate wage premiums due to job investments and lack of bargaining power. ${ }^{247}$ Employers and chemical manufacturers would have the same disincentives to test chemicals and generate information. Even more problematic, OSHA would be unable to promulgate the opt-out standards in the first instance, given that it lacks the resources necessary to conduct toxicity testing on the thousands of untested chemicals in the marketplace. And for those chemicals that are left untested, and therefore without a governing opt-out regulation, the risk/precaution incentives and the compensatory schemes would essentially be the same as the status quo. Asking OSHA to develop even opt-out regulations, without altering the incentives for the least-cost information generators-employers and chemical manufacturers-will not close the information gap.

Opt-out regulations would fail in the context of chemical exposures for yet another reason-the negative externalities outlined in Part III.B. Professor Lambert's proposal assumes that most employers will want to meet the suggested optional regulations because they are cost-effective and reduce the amount of ex post compensation an employer will be required to pay for on-thejob injuries. ${ }^{248}$ But unique characteristics of illnesses caused by chemical exposures, including long latency periods, toxicity uncertainty, and potential confounding factors allow employers to shift costs onto employees, insurers, and taxpayers. Employers and manufacturers never bear the full expected costs of the exposure risk, making opt-out regulations ineffective.

\section{Combining Social Insurance Programs and Risk-Based Taxes}

A number of other scholars have focused on reforming the compensatory system to achieve more efficient levels of risk and precaution. Professor Viscusi has proposed compensating all worker diseases, regardless of cause, from social security programs, while funding the programs with special risk-based taxes on employers. ${ }^{249}$ Similarly, Professor Frances Edwards advanced a proposal that the federal government create a special fund to compensate all victims of latent occupational disease, with funding coming from a payroll tax. ${ }^{250}$ The amount of payroll tax would be adjusted by NIOSH to impose higher taxes on those

247 See supra notes 217-18, 243 and accompanying text.

248 See Lambert, supra note 9, at 1071 ("If the substantive requirements of an opt-out regulation were truly cost-effective...then employers would tend to adopt them voluntarily - that is, they would choose not to opt out. Employers who could not cheaply comply and for whom the expected savings in injury costs were less than the costs of compliance, however, would not be forced to adopt an inefficient precaution as long as they provided the information that would ensure that they ended up paying (in the form of risk premiums) the full costs of risks they impose.").

249 See Viscusi, supra note 4 , at 77.

250 See Edwards, supra note 217, at 42-43. 
employers whose operations create more risk to employee health than ordinary business operations. 251

These proposals would be effective in spreading the expected costs of latent worker disease broadly amongst the population, but they would not likely close the toxicity information gap. Social security type programs will be unlikely to fundamentally change the incentives of employers and chemical manufacturers. Because of imperfections in the ability of NIOSH (or other regulatory bodies) to accurately set risk-based taxes-especially in the absence of new toxicology studies - most employers will likely be content to pay the imposed tax, rather than make costly expenditures on new research on their substances. Further, the Viscusi and Edwards proposals may actually exacerbate the negative externalities from which employers now benefit. If the risk-based taxes are inaccurately set, due to poor estimates of the expected costs imposed by any particular employer, then employers will not bear an appropriate portion of the ex post compensation for an employee who contracts an occupational disease. The employee's relief would come from a general fund, not from an insurance policy held by the specific employer in question, with corresponding premiums that may adjust according to an employer's particular experience rating. Nor will employers be likely to pay any significant ex ante wage premium for risky jobs, since-assuming the compensation system is sufficient-employees will know that a federal social security program will compensate them for any latent diseases. In these ways, a general compensation fund for occupational diseases may actually exacerbate the incentive for employers to use untested chemicals and the disincentive for employers to help develop new toxicity information.

Finally, it is not clear how these programs would include chemical manufacturers, the true least cost risk avoiders and least cost information generators, in the general compensation scheme. If chemical manufacturers are included in the system only in their capacity as employers, and not in their dual capacities as employers and producers of potentially harmful chemical products, then they will bear an insufficient amount of the cost of ex post compensation of disease victims (in the form of their share of risk-based taxes on employers). Risk-based taxes on chemical manufacturers calculated only by looking at the risk that such manufacturers impose on their own employees ignores a large part of the negative externality that manufacturers exploit through the toxicity uncertainty of their chemicals. Chemical manufacturers impose some of the expected costs of their products on employees who work with their products in the manufacture of other goods further down the production chain. In order to properly incentivize chemical manufacturers, they must bear a much larger share of the ex post compensation for disease than they do under the current regime.

While the proposals advanced by Viscusi and Edwards would make strides toward accomplishing the compensatory goal of the worker safety regime, they

${ }^{251}$ Id. at 42. 
do not appear well-suited to accomplishing the first goal-achieving an efficient level of risk and precaution.

\section{Public Nuisance Actions Requiring Testing}

Recently, Professor Albert Lin has suggested a new and intriguing approach to chemical testing-using public nuisance tort claims to require chemical manufacturers to test their products. ${ }^{252}$ Although Professor Lin's proposal is focused on the problem of insufficient chemical testing in general, and not specifically on workplace exposures, his proposal would nonetheless influence the worker disease regime. Under Professor Lin's proposal, states could bring civil public nuisance claims against chemical manufacturers seeking only injunctive relief. ${ }^{253}$ The injunctions sought would require testing on a given chemical before it may be sold or distributed within the state. ${ }^{254}$

The public nuisance proposal has the advantage of requiring no change in the law, other than perhaps a more expansive view of the reach of public nuisance tort claims than might currently be accepted by some courts. ${ }^{255}$ It also has the benefit of not imposing a crushing litigation burden on chemical manufacturers, since only public entities would be able to bring these failure-totest claims, and the claims could be selectively chosen given the limited resources of the state attorneys general. ${ }^{256}$ But this admitted advantage may also be the biggest shortcoming of the proposal. There is no reason to expect state attorneys general to devote significant resources to identifying which of thousands of chemicals should be the subject of a failure-to-test suit. Moreover, the long latency period of diseases caused by exposures means that the public may not consider the pursuit of such claims a high priority, leaving little political pressure on attorneys general to pursue them.

More importantly, these public nuisance suits would not alter the incentives of employers and manufacturers, and would not ensure the adequate compensation of victims. The injunctions, if awarded, might lead to compliance and new testing as to any specific, identified chemicals. But in the absence of a fine or some other type of penalty, there would be little or no deterrent effect. Chemical manufacturers would have the same disincentives to generate toxicity information and would comply with a testing injunction only when an attorney general singles out one of their chemicals. Otherwise, it would be business as usual for chemical manufacturers. Nor would the public nuisance suits cure the ex post compensation problem. New testing on certain selectively chosen chemicals would do nothing to compensate employees already suffering from

252 See Lin, supra note 1, at 958.

253 Id. at $990-91$.

254 See id.

255 See id. at $986-87$.

256 See id. at 999 ("Public nuisance actions not only can target individual chemicals for testing, but their case-specific approach also allows testing requirements to be tailored to fit specific situations."). 
diseases caused by exposure to substances that did not catch the attention of the attorneys general.

\section{E. Amending the OSH Act to Categorize Hazards and Shift Burdens for High-Risk Hazard Categories}

Professor Shapiro and Professor McGarity have proposed a type of burden shifting that focuses on OSHA standards rather than on the proof of causation. ${ }^{257}$ Under their proposal, OSHA would create categories of industrial hazards. ${ }^{258}$ Any industry in which workers are exposed to chemicals that OSHA has identified as those that "could reasonably be anticipated to cause a material impairment of health or functional capacity" would initially be categorized as Class II industries. ${ }^{259}$ Those industries would be required to install "best available workplace risk reduction technology" (BAT) by specified deadlines. ${ }^{260}$ If the BAT requirement and regulation under Class II were deemed insufficient by OSHA, it could redesignate the industrial hazard to Class I.261 This would require employers to reduce exposure to the extent "feasible," which would impose a more significant and expensive burden on employers than a BAT requirement. ${ }^{262}$ OSHA could also identify certain highrisk operations within Class I and require permitting for those industries. ${ }^{263}$

Under the plan suggested by Professor McGarity, regulated employers or trade associations could petition OSHA to "redesignate an industry to the least stringently regulated Class III upon a demonstration that employees in the industry could not reasonably be anticipated to suffer 'material impairment of health or functional capacity" under any realistic exposure scenarios."264 With this option, industry would "bear the burden of demonstrating that employee exposure to the listed substance was so trivial as to reduce the risk of harm to acceptable levels." 265

This plan has the definite advantage of relieving OSHA of at least some of the burden of defending its standards under the significant risk and feasibility tests. ${ }^{266}$ But it falls short of providing a comprehensive solution to the worker disease problem. First, this plan begins from the assumption that OSHA can accurately identify a list of chemicals that may pose health hazards, from which

${ }^{257}$ See generally Sidney A. Shapiro \& Thomas O. McGarity, Reorienting OSHA: Regulatory Alternatives and Legislative Reform, 6 YALE J. ON REG. 1 (1989). See also McGarity, supra note 9, at 107.

258 Shapiro \& McGarity, supra note 257 , at 47.

${ }^{259}$ Id.

$260 \mathrm{Id}$.

261 Id.

262 See id. at $47-48$.

263 See McGarity, supra note 9, at 108.

${ }^{264} \mathrm{Id}$. at 108 .

265 Id.

266 See supra notes 189-90, 194 and accompanying text. 
OSHA can begin the categorization. Whether OSHA has the resources, information, and expertise to accomplish this is questionable. Consider whether diacetyl would have made such a list as of the mid-1990s, when BASF had unpublished information on the dangers of diacetyl inhalation, but the FDA had declared diacetyl "generally recognized as safe." 267

Second, this plan would not change the compensatory system, and therefore would not cure the market's inability to efficiently set risk and precaution levels. Although the plan would facilitate the process of promulgating OSHA command and control regulations, and might incentivize the production of new scientific information regarding toxicity, it would not change the ex post compensation scheme under state workers' compensation laws. Victims of occupational disease would remain undercompensated, and employers and manufacturers would continue to externalize a significant chunk of the expected costs of diseases caused by worker exposures.

Third, this proposal does not appear to directly involve chemical manufacturers and suppliers in the compensation process. Although manufacturers of a particular chemical may wish to assist certain industries in achieving a Class III designation, their incentive will likely be only indirect, through the demand for their chemical product used in a manufacturing process further down the production chain. This could be an insufficient financial incentive to spur chemical manufacturers-those in the best position to generate information-to develop new toxicity information. As explained above, many manufacturers (such as the microwave popcorn manufacturers) lack information about the exposure risks posed by-and sometimes even the chemical identities of - the substances they use in their manufacturing process. ${ }^{268}$ Such employers would be unable to meet the burden proposed by Professors McGarity and Shapiro without assistance from chemical manufacturers. Without sufficient financial incentives, chemical manufacturers will not likely be willing to conduct new testing to help employers meet this burden.

Professor McGarity states: "Although [this] proposal is certainly not the only possible burden shifting device, some kind of procedural vehicle to shift the burden of justification is necessary if OSHA is to have any hope of accelerating the ponderous pace of its standard-setting efforts." 269 With this statement, I concur. But I would submit that a more comprehensive and fundamental change in the workplace disease regime requires addressing not just OSHA's command and control standards, but also the workers' compensation system. The inclusion of chemical manufacturers in the compensation system is necessary to provide more effective incentives for chemical manufacturers to join OSHA's efforts and push for new exposure standards.

26721 C.F.R. $\$ 184.1278$ (1983); see also supra notes $25,27-28$ and accompanying text.

268 See supra note 67 and accompanying text.

${ }^{269}$ McGarity, supra note 9, at 109. 


\section{F. The REACH Model}

Finally, the United States could follow the model of the EU's chemical registration legislation, known as REACH, which became effective in EU member nations in June 2007. ${ }^{270} \mathrm{REACH}$ generally adopts a precautionary approach to the introduction of chemicals into the marketplace. Instead of presuming that all industrial chemicals are innocent until proven guilty, REACH requires that chemical manufacturers prove the safety of at least some chemicals before they can market them. ${ }^{271}$

Regulation under REACH is tiered, based in part on the volume of the chemical produced. ${ }^{272}$ REACH provides for the registration of all chemicals produced or used in quantities exceeding one ton per year. ${ }^{273}$ Registration involves the submission of a dossier on the chemical listing any relevant health hazard information. ${ }^{274}$ The amount and type of information required varies with the type and volume of the chemical, as well as the previously known safety concerns relating to the chemical. ${ }^{275} \mathrm{~A}$ failure to register results in a ban on the manufacture or import of the chemical. 276

Reaction to REACH by chemical manufacturers in the U.S. market has been predictably negative. ${ }^{277}$ Currently, the passage of legislation like REACH in the United States seems politically unlikely. My more moderate proposal would not mandate that the industry perform new research on all high volume chemicals, but instead would provide financial incentives to spur such research. A proposal that is based on correctly aligning the financial incentives of the relevant parties, so that economic externalities are internalized by the market participants, may be more likely to succeed in the United States than a proposal for increased direct regulation.

Aside from practical political considerations, there are other problems with REACH. Providing a tiered structure and limiting registration to relatively high volume chemicals may miss chemicals with harmful health effects. ${ }^{278}$ Further, the REACH model envisions that regulators would review for reliability only a small portion of the data submitted, and regulators would be required to sort out

270 See Leslie E. Kersey, Note, Trans-Atlantic REACH: The Potential Impact of the European Union's New Chemical Regulations on Proof of Causation in U.S. Federal Courts, 36 B.C. ENvTL. AfF. L. REV. 535, 537-39 (2009) (contending that the EU's REACH requirements may have some limited impact on proof of causation in toxic tort claims in the United States); see also CoLLINS, supra note 193, at 123-24.

271 See COLLINS, supra note 193, at 123.

272 See Adelman, supra note 233, at 392.

273 See Kersey, supra note 270 , at 542.

274 Id.

$275 \mathrm{Id}$.

276 Id.

${ }^{277}$ Id. at $538-39$.

278 See COLLins, supra note 193, at 123 n.32 (noting that Greenpeace and others have criticized as too limited the scope of chemicals covered under the first REACH list of covered chemicals). 
which chemicals to prioritize. Chemical manufacturers would continue to have an incentive to submit minimal data, or mere plans for testing rather than results, in hopes that the majority of their chemicals will fall through the quality control cracks of REACH. Indeed, REACH contains exceptions for certain chemicals, manufacturers, and importers, to provide that only study proposals or protocols are needed to secure registration and allow marketing of the chemical. ${ }^{279}$

Further, unlike REACH, my proposal will leave chemical manufacturers with a choice about conducting additional, expensive studies: if they anticipate that a particular chemical is likely to be harmful or likely to draw a number of workers' compensation claims, they can attempt to establish an OSHA PEL and develop the data supporting the PEL. If, on the other hand, existing studies or the chemical's structure convince the manufacturers that the chemical is likely to be benign, then the manufacturers can choose not to push for an OSHA PEL and save the expense of conducting additional toxicity studies. Notably, the chemical manufacturers are precisely the entities in the best position to make that cost-benefit evaluation; they know the most about the structure and potential dangers of the chemical. REACH does not permit this type of costbenefit evaluation by the manufacturers. ${ }^{280}$ Instead, it simply requires compliance with the governmentally imposed registration regulations, and leaves to government regulators all decisions about which chemicals must be registered. ${ }^{281}$

Finally, the REACH model, like Professor Lyndon's super study proposal, will likely fail to adequately change risk/precaution allocations and thereby fail to satisfy the compensation goal of the workplace safety regime. Chemical manufacturers and employers using chemicals regulated under a registration system will submit the minimum information necessary to secure registration of their chemicals. That information may help some claimants establish causation in workers' compensation (or tort) at the margins, but it will not likely bring ex post compensation up to the levels necessary to force chemical manufacturers and employers to internalize the full expected costs of the chemicals they use.

${ }^{279}$ Kersey, supra note 270 , at 561.

280 See generally Regulation 1907/2006, of the European Parliament and of the Council of 18 December 2006 Concerning the Registration, Evaluation, Authorisation and Restriction of Chemicals (REACH), Establishing a European Chemicals Agency, Amending Directive 199/45/EC and Repealing Council Regulation (EEC) 793/93 and Commission Regulation (EC) 1488/94 as well as Council Directive 76/769/EEC and Commission Directives 91/155/EEC, 93/67/EED, 93/105/EC and 2000/21/EC, 2006 O.J. (L 396) 1 (EC).

281 See Noah M. Sachs, Jumping the Pond: Transnational Law and the Future of Chemical Regulation, 62 VAND. L. REV. 1817, 1834-38, 1842-44 (2009) (describing $\mathrm{REACH}$ registration requirements and some costs of implementation). 


\section{Proposed Solution: GetTing Employers and Chemical MANufacturers to Push FOR New EXPOSURE STANDARDS}

\section{A. Proposal Goals and Features}

The key to reviving the current three-pronged worker disease regime is to recognize and address the sources of market and regulatory failure. Any proposal should have, as its primary goal, capitalizing on the financial incentives facing the least-cost information providers and least-cost risk avoiders. ${ }^{282}$ In this Part, I detail my proposal for accomplishing that goal. My proposal contains two main features: (1) a default burden allocation framework on the issue of disease causation, and (2) expansion of workers' compensation proceedings to include chemical manufacturers.

\section{Proposal Feature 1: A Default Burden Allocation Framework}

The key component of my proposed reform is establishing a default burden allocation rule on the question of causation in employees' claims for ex post compensation for workplace disease. This default burden allocation would provide that if a claimant can present some minimal, prima facie evidence of causation, then the burden of disproving causation will be on the employer. The prima facie evidence may consist of a single animal or epidemiological study, a study regarding the chemical's pharmacokinetic properties, or an expert opinion regarding the "biological plausib[ility]"283 of causation based on analysis of chemical structure, pharmacokinetic mechanisms, or comparison to other chemicals or compounds whose health effects have been studied. To meet her prima facie burden, the claimant would also need to produce some evidence tending to show that she was exposed to the chemical or substance while working for the employer. In practice, the claimant's prima facie case would be similar to, and perhaps even more demanding than, the preliminary link showing required for shifting the burden of production under Alaska's workers' compensation law. ${ }^{284}$

282 Others have described and advocated analogous regulatory default rules in the context of environmental law. See, e.g., Bradley C. Karkkainen, Information-Forcing Environmental Regulation, 33 FLA. ST. U. L. REV. 861, 869 (2006) ("Regulatory penalty default rules may also be information-forcing in the additional sense that they induce regulated parties to produce new information that may be required to construct the proposed alternative and secure its approval. This feature is likely to be especially useful when the regulated party does not presently hold the desired information but is the party best situated to produce it - a common occurrence in environmental regulation." (second emphasis added)).

283 See U.S. Fed. Judicial Ctr., Reference Manual on Scientific Evidence 201 (1994).

${ }^{284}$ See supra notes $167-71$ and accompanying text. For example, the Alaska Supreme Court found that one physician's testimony that he believed the claimant's disease to be "secondary to airborne chemical burn ... perpetuated by continued exposure to sulfur 
Claimant's prima facie evidence would be required to meet the standards for admissibility and consideration of expert testimony in workers' compensation proceedings in the jurisdiction, which is typically relaxed from the common law or statutory rules of evidence. ${ }^{285}$ No rule of admissibility, however, should operate to exclude proffered evidence simply because it is based on animal studies. The use of animal studies as evidence of causation in legal proceedings is controversial. ${ }^{286}$ However, as the diacetyl case demonstrates, animal studies like the BASF study can be early indicators of potential toxicity and of the need to develop further information. ${ }^{287}$ Moreover, human epidemiological studies are often unavailable for newer compounds and human experimental trials are obviously unethical outside the arena of experimental drug testing. If the policy goal of the proposed liability regime is to spur chemical manufacturers and employers to conduct the testing necessary to close the information gap and set an appropriate OSHA exposure limit standard-especially for new chemicals - then animal studies must be considered sufficient to establish a prima facie case in workplace disease law. ${ }^{288}$

If claimant meets her prima facie burden, then the burdens of production and persuasion on the element of causation would be shifted to the employer. ${ }^{289}$ The employer can disprove causation by coming forward with sufficient evidence to convince the trier of fact, by a preponderance of the evidence, that

dioxide and chlorine" was sufficient to shift the burden of production. La. Pac. Corp. v. Koons, 816 P.2d 1379, 1381 (Alaska 1991) (alteration in original); see also supra note 171 and accompanying text.

285 See, e.g., N.Y. WORKERS' COMP. LAW $§ 118$ (McKinney 2005) (in making investigation or conducting a hearing the chairman or board is "not . . . bound by common law or statutory rules of evidence"); see also Gen. Elec. Co. v. Joiner, 522 U.S. 136, 145-47 (1997) (affirming the exclusion of expert evidence including human epidemiological studies and animal studies); Daubert v. Merrell Dow Pharm., Inc., 509 U.S. 579, 592-93 (1993) (requiring courts considering the admissibility of scientific expert testimony to make "a preliminary assessment of whether the reasoning or methodology underlying the testimony is scientifically valid and of whether that reasoning or methodology properly can be applied to the facts in issue").

286 See Erica Beecher-Monas, A Ray of Light for Judges Blinded by Science: Triers of Science and Intellectual Due Process, 33 GA. L. REV. 1047, 1079-80 (1999); Neal C. Stout \& Peter A. Valberg, Bayes' Law, Sequential Uncertainties, and Evidence of Causation in Toxic Tort Cases, 38 U. MiCH. J.L. REFORM 781, 816-17 (2005); Amanda Hungerford, Note, Back to Basics: Courts' Treatment of Agency Animal Studies After Daubert, 110 Colum. L. REV. 70, 70 (2010).

287 See supra notes $27-29$ and accompanying text.

${ }^{288}$ See generally MICHAELS, supra note 51, at 25 ("Animal studies are important, but manufacturers often hold out for epidemiological evidence with humans before accepting any label that a substance is a carcinogen. Alternatively, they will hold out for animal studies if the only existing evidence comes from epidemiologic studies.").

${ }^{289} \mathrm{~A}$ shift in the burden of persuasion distinguishes this proposal from the current workers' compensation laws in Alaska and the District of Columbia. See supra notes 16970,173 and accompanying text. 
exposure to the chemical in question did not cause the claimant's disease or illness. 290

This burden allocation framework is loosely patterned after the type of burden-shifting frequently used in employment discrimination cases. ${ }^{291}$ The justifications for burden-shifting on the question of causation in occupational disease cases are similar to those at work in discrimination cases: judicial estimates of the information costs facing each litigant on the element in question (here, disease causation; in employment cases, discriminatory motive), combined with judicial estimates of probabilities on the merits of the element in question, after taking into account the evidence constituting the prima facie case, can justify shifting the burden of proof onto the defendant. ${ }^{292}$

Evidence on the element of causation is generally elusive in the context of chemical exposures and is more likely to be in the possession or control of the employer than the employee. As between the employee and the employer, the employer is the lesser-cost risk avoider and the lesser-cost information generator on chemical exposures. Additionally, the required prima facie showing forces the claimant to show, at least minimally, some probability that exposure to the chemical caused the ailment. The relative information costs facing the parties, combined with a prima facie showing on the probability of causation, is sufficient to justify altering the usual allocation of the burdens of proof. 293

Employers would not be locked into this burden-shifting framework, however. To encourage the production of toxicity information, my proposal would offer employers a way out of bearing the burden of proof on causation: enforceable OSHA standards. If a permanent OSHA PEL standard is in place for the chemical, then the foregoing burden-shifting framework would not apply. Rather, the burden of proof on causation would remain on the claimant.

290 In the context of reproductive and genetic workplace hazards, Professor Jean Macchiaroli Eggen proposed a similar burden-shifting scheme, although without a safe harbor provision to trigger information production by employers, and without an expansion of workers' compensation coverage to reach product manufacturers. See Jean Macchiaroli Eggen, Toxic Reproductive and Genetic Hazards in the Workplace: Challenging the Myths of the Tort and Workers' Compensation Systems, 60 FordHAM L. Rev. 843, 899-905 (1992).

291 See Price Waterhouse v. Hopkins, 490 U.S. 228, 267 (1989) (O'Connor, J., concurring), superseded by statute, Civil Rights Act of 1991, Pub. L. No. 102-166, 105 Stat. 1074, 42 U.S.C. $\$ 2000 \mathrm{e}-2$ (a)(1) (2006); Int'1 Bhd. of Teamsters v. United States, 431 U.S. 324, 360-61 (1977); McDonnell-Douglas Corp. v. Green, 411 U.S. 792, 802-03 (1973).

292 Price Waterhouse, 490 U.S. at 267 (O'Connor, J., concurring) ("[O]ur decisions in Teamsters and Franks do indicate a recognition that presumptions shifting the burden of persuasion based on evidentiary probabilities and the policies behind the statute are not alien to our Title VII jurisprudence.").

293 Id.; see also Fleming James, Jr., Geoffrey C. HaZArd, Jr., \& John Leubsdorf, Civil Procedure $\$ 7.16$ (5th ed. 2001); Edward W. MCCleary et Al., MCCormick on Evidence $\$ \S 337,343$ (2d ed. 1972); 9 JOHN HeNRY Wigmore, EvidENCE IN TRIALs AT COMMON LAW $\S 2486$ (James H. Chadbourn ed., 1981). 
For chemicals or substances specifically governed by an OSHA permanent standard, the claimant would bear the burden of proving either: (1) by a preponderance of the evidence, that she was exposed at levels exceeding the PEL; or (2) by clear and convincing evidence, that her disease was caused by exposure to the substance, even though she was exposed at or below the PEL. ${ }^{294}$

Using a default burden allocation framework will provide employers with an economic incentive to push for the adoption of permanent OSHA regulations setting PELs that employers can realistically meet. To do so, employers will have an incentive to ensure that OSHA obtains sufficient information to satisfy the significant risk and feasibility requirements of the OSH Act, as interpreted by the Supreme Court. This includes developing and presenting to OSHA evidence on both the toxicity of a substance and the feasibility of meeting various possible PELs for the substance. In other words, employers will have an incentive to provide information on both the risks of exposure and the costs of taking precautions. ${ }^{295}$ By changing the incentives to produce information, this approach would specifically target the first area of market failure-information deficiency. ${ }^{296}$

294 On the second point, states might be encouraged to make an election on the standard of proof. That is, some states might prefer to enact a statute providing that if there is a governing OSHA PEL, the claimant may nonetheless prevail by proving by a preponderance standard that her disease was caused by exposure to the substance, even though she was exposed at or below the PEL. States taking this approach would reduce the overall incentive for employers and chemical manufacturers to seek PELs. On the other hand, a clear and convincing standard may result in an excessive number of meritorious claims being denied. Striking the right balance on the standard of proof in this situation could be left to state legislatures, and the resulting empirical evidence could later be compared across jurisdictions.

${ }^{295}$ One lingering concern is outdated PELs based on old scientific information. Due to information problems and the requirements imposed on OSHA by the courts, most of the current permanent PELs are based on scientific information from the 1960s. Kyle W. Morrisson, Reaching the Limit on PELs: Calls Increase for OSHA to Update Decades-Old Regulation, NAT'L SAFETY COUNCIL, http://www.nsc.org/safetyhealth/Pages/510PELs.aspx (last visited Nov. 8, 2012); see also McGarity, supra note 9, at 101. As a result, employers might be able to take advantage of the proposed safe harbor provision on the basis of an outdated and inadequate PEL. This concern can be addressed in a manner consistent with my proposal in one of two ways: (1) amend the OSH Act to include a sunset provision for permanent PELs, so that they must be regularly reviewed and updated on the basis of new scientific information; or (2) encourage states to include in their workers' compensation amendments a condition that the applicable OSHA standard must have been adopted, updated, or reviewed by OSHA within a set period of time prior to the alleged exposures. If the OSH Act is not amended to provide a uniform national updating requirement, then states adopting my proposal could be encouraged to experiment with different approaches to the problem of outdated PELs.

296 This type of default burden allocation is similar to the types of "penalty default rules" that have been advocated in other contexts by professors Ian Ayres and Robert Gertner. See Ian Ayres \& Robert Gertner, Filling Gaps in Incomplete Contracts: An Economic Theory of Default Rules, 99 YALE L.J. 87, 91 (1989); Ian Ayres \& Robert Gertner, Majoritarian vs. Minoritarian Defaults, 51 STAN. L. REV. 1591, 1591 (1999); see also 
This approach would also reduce the employer's ability to impose negative externalities. Where OSHA does not have sufficient new information to promulgate a governing PEL, causation remains murky, and latency periods prevent the identification of causal factors, the employer will bear the burden of disproving causation. Conversely, where OSHA obtains sufficient information to identify and enforce a PEL, the effects of latency and scientific uncertainty will be reduced by the new information. Employers will be forced to internalize more of the expected costs of the risks they impose through the use of hazardous chemicals in the workplace, because the ex post compensation system will benefit from the new information.

\section{Proposal Feature 2: Expanding Worker Disease Statutes to Cover Chemical Manufacturers}

The burden-shifting framework outlined above will do little good if employers are not in a position to cost-effectively develop and produce to OSHA new scientific information about toxicity and precaution costs. Employers, like employees, may face insurmountable information generation costs. Removing the economic disincentive to provide information may not be sufficient. Many, if not most, employers will not be in a position to costeffectively conduct or sponsor animal or epidemiological studies on every chemical compound or substance they use in their manufacturing process. Even where some employers have such resources, they may be inclined to free ride off of other employers if they know that the other employers use the same chemicals and will likely develop the information necessary to support an OSHA standard. Among employers using the chemical, the toxicity and feasibility information will be a public good. All employers using the chemical will get the benefit of an OSHA standard regardless of which employer actually spends the resources to develop and produce the information necessary to support the standard.

One cause of this problem is that the current worker safety regime does not effectively incorporate the true least-cost risk avoiders, the true least-cost information generators, and those who have the most direct economic interests in the regulation of chemicals - the chemical manufacturers themselves. ${ }^{297}$

Karkkainen, supra note 282 , at 865-66 (drawing upon the "penalty default" model and advocating, in the environmental context, regulatory default rules that impose "harsh background regulatory requirements coupled with an opportunity for regulated parties to 'bargain around' the default baseline by securing regulatory approval for alternative arrangements"); Wagner, Commons Ignorance, supra note 17, at 1741.

${ }^{297}$ Most current state workers' compensations laws provide that an employer (or its insurer) that pays workers' compensation benefits to an employee-claimant is subrogated to the employee's tort claim against a third party, and that the employer may pursue a claim against the third party if the employee chooses not to do so. See, e.g., Fla. STAt. Ann. $\S 440.39$ (West 2006); IND. CODE ANN. $\$ 22-3-7-36$ (West Supp. 2012); KY. REv. STAT. ANN. $\$ 342.700$ (LexisNexis 2011); MinN. STAT. ANN. $\S 176.061$ (West 2012); Mo. ANN. 
Chemical manufacturers have the most at stake in any direct regulation of a particular chemical. If the worker safety regulatory regime does not include chemical manufacturers in some meaningful way, then they will remain free to exploit the market failures attendant to the risks their chemical products impose. The first feature of my proposal will put some incremental increased economic pressure on chemical manufacturers to produce more information. If some employers cease, or threaten to cease, using a chemical for which OSHA has no standard in order to avoid the burden shift, then chemical manufacturers may feel pressure to pursue a PEL for that chemical. But more direct and significant economic pressure could be applied to chemical manufacturers if they were directly incorporated into the governing liability scheme.

Thus, the second feature of my proposal is to expand the reach of workers' compensation laws to include chemical manufacturers and suppliers. Employers responding to workers' compensation claims would be permitted to name as third-party respondents in the workers' compensation proceeding any chemical manufacturer that supplied the employer with any quantity of the chemical that the claimant alleges caused her disease. Importantly, the burden of proof framework described above as the first feature of my proposal would be equally applicable to this third-party type claim. Where, in the absence of an OSHA regulation, an employee-claimant makes the required prima facie showing, the burden would be on the employer to disprove causation. However, the employer would be able to impose any resulting liability on the third-party respondent chemical manufacturer under the same proof scheme. As a result, where there is no OSHA regulation the employer will still be able to avoid paying ex post compensation claims to the employee (or increased premiums as a result of adverse experience ratings) if it names the supplying chemical manufacturer as third-party respondent and the chemical manufacturer is unable to satisfy the burden of disproving causation. A chemical manufacturer would have a defense against the employer if it can affirmatively establish that the employer used the

STAT. $\$ 287.150$ (West Supp. 2012); N.Y. WORKERS' COMP. LAW $\S 227$ (McKinney 2005); OKLa. Stat. AnN. tit. 85, $\$ 348$ (West 2012); 77 PA. CONS. STAt. AnN. $\S 1419$ (West 2002); Tenn. Code AnN. \$50-6-112 (2008); Tex. Lab. Code AnN. $\$ 417.001$ (West 2012); VA. CODE ANN. § 65.2-309 (2007); W. VA. CODE ANN. §23-2A-1 (LexisNexis 2010); WIS. Stat. ANN. $\$ 102.29$ (West 2011); see also Andrew R. Klein, Apportionment of Liability in Workplace Injury Cases, 26 BERKELEY. J. EMP. \& LAB. L. 65, 67 n.7 (2005) (noting that most states still permit employers to recover the full cost of any paid workers' compensation benefit from a third-party tortfeasor). Under these laws, however, the employee or the subrogated employer or insurer will only prevail against a third-party chemical manufacturer if it can establish liability under the state's tort laws. For the reasons discussed more fully supra Part IV.B, tort theories, including defective product or failure to warn theories, are generally ill-suited to chemical exposure claims and are insufficient to prevent chemical manufacturers from externalizing much of the expected costs of their products. Internalization of those expected costs requires that chemical manufacturers be subjected to the proof standards I have proposed for workers' compensation claims. Exposing chemical manufacturers to the shifting proof standards set forth above would force manufacturers to internalize a more substantial share of the expected costs of their products. 
chemical in a manner contrary to the recommendations of the MSDS, or that the employer failed to take precautions recommended by the MSDS.

Adding chemical manufacturers directly into the ex post compensation scheme is crucial, because it ensures the involvement of the least-cost risk avoider and the least-cost generator of chemical toxicity information. It will directly incentivize chemical manufacturers to generate and produce toxicity and feasibility information (rather than indirectly incentivize them through the market demand for its chemicals). Chemical manufacturers will no doubt contend that this proposal would subject them to crippling liability for employee illnesses and impossibly heavy burdens to produce scientific information on their products. It will certainly shift a greater share of the costs of scientific uncertainty onto chemical manufacturers. But this argument ignores the benefits that have been inefficiently and unjustly enjoyed by the chemical manufacturers to this point. The "innocent until proven dangerous" approach to chemical regulation has permitted chemical manufacturers to profit from uncertainty and negative externalities for decades. A negative impact on chemical manufacturers is not a reason to reject the proposal; rather, it is the natural and expected result of a proposed reform that forces the internalization of expected costs of exposure risks.

Further, chemical manufacturers will be able to spread the costs of this risk the same way that employers do now, through the purchase of workers' compensation insurance policies. The price of insurance will likely be passed through, to some extent, in the form of increased chemical prices. But this will simply ensure that the full expected costs of chemicals are borne by the employers that use potentially risky chemicals and the purchasers of products that require the use of such chemicals in the manufacturing process. The market will be able to arrive at efficient levels of risk and precaution: the expected costs of risky chemicals will be re-introduced into the price for those chemicals and, in turn, the price of goods manufactured with these chemicals. The price of the end product will more accurately reflect the expected costs imposed by the manufacture of that good. Consumers will pay higher prices for goods created using potentially hazardous, untested, and unregulated chemicals, creating competitive pressure to use chemicals governed by OSHA exposure limits. This is a significant improvement over the status quo, where much of the expected cost of using a risky or untested chemical is externalized to the general public and taxpayers through burdens on workers, their families, social security programs, and the general health insurance industry.

\section{B. Implementation: A New National Commission on State Workers' Compensation Laws and Recommended State Statutory Amendments}

My proposed reforms could be accomplished by amending state workers' compensation laws to provide for a default burden-shifting framework and to include in the liability apportionment scheme the suppliers of chemicals used in the workplace. These changes could be recommended by a new National 
Commission on State Workmen's Compensation Laws (NCSWC). In 1970, Congress created a NCSWC to comprehensively review the adequacy of state workers' compensation laws. ${ }^{298}$ The prior NCSWC found state workers" compensation laws were, at the time, "neither adequate nor equitable." 299 The NCSWC made nineteen "essential" recommendations for reforming state workers' compensation laws. ${ }^{300}$ The NCSWC warned that federal workers' compensation legislation might be required in the absence of prompt reform of the deficiencies at the state level. ${ }^{301}$ The states implemented, at least to some degree, most of the recommendations of the NCSWC, resulting in more extensive workers' compensation coverage and benefits for injured workers. ${ }^{302}$

A new NCSWC should be created and specifically instructed to address the market failures and regulatory shortcomings of state workers' compensation systems regarding occupational disease. ${ }^{303}$ As with the 1972 Report, a NCSWC

298 NAT'L COMM'N ON STATE WORKMEN'S COMP. LAWS, REPORT OF THE NATIONAL COMMISSION ON STATE WORKMEN's COMPENSATION LAWS 3-4 (1972), available at http:// www.workerscompresources.com/National_Commission_Report/national_commission report.htm.

299 Id. at 25 .

300 Id. at 26.

$301 \mathrm{Id}$.

302 See NAT'L ACAD. OF SOC. InS., ADEQUACY OF EARNINGS REPLACEMENT IN Workers' Compensation Programs: A Report of the Study Panel on Benefit Adequacy of the Workers' Compensation Steering Committee 15 (H. Allan Hunt ed., 2004) ("The states did make a significant effort to comply, and through the decade of the 1970 s benefits generally were increased and eligibility was expanded."); see also U.S. DEP'T OF LABOR REPORT, STATE WORKERS' COMPENSATION LAWS IN EFFECT ON JANUARY 1, 2004 Compared With the 19 Essential ReCommendations of the National Commission on STATE WORKMEN'S COMPENSATION LAWS (2004), available at http://www.workers compresources.com/National_Commission_Report/National_Commission/1-2004/Jan2004 nat com.htm. The NCSWC was charged with undertaking "an effective study and evaluation of State workmen's compensation laws in order to determine if such laws provide an adequate, prompt, and equitable system of compensation" and to determine whether federal legislation was necessary to improve such programs. 29 U.S.C. $\$ 676$ (2006); see also NAT'L ACAD. OF SOC. INS., supra, at 7.

303 In 2009, a bill was introduced in the U.S. House of Representatives to create a new NCSWC. See National Commission on State Workers' Compensation Laws Act of 2009, H.R. 635, 111th Cong. (2009). This bill would direct the new NCSWC to evaluate a number of items related to workers' compensation benefit and coverage. Id. $\S 4(\mathrm{~b})$. Although adequate coverage of workplace injuries and diseases is a general subject for review, H.R. 635 does not specifically require review of standards for establishing causation in chemical exposure cases, nor does it specifically direct the consideration of potentially expanding workers' compensation laws to reach chemical manufacturers. See H.R. 635. The U.S. Chamber of Commerce opposed this legislation, contending that it would "serve as a vehicle to undermine state-based workers" compensation systems" and would "drastically increase costs for every employer." Letter from U.S. Chamber of Commerce et al. Opposing H.R. 635, to the Members of the United States House of Representatives (Apr. 28, 2009), available at http://www.uschamber.com/issues/letters/2009/multi-industry-letter-opposinghr-635-national-commission-state-workers-compensa. H.R. 635 was referred to the House 
recommendation on occupational diseases related to chemical exposures could be backed by the threat of potential national legislation on occupational diseases. 304

Below is one concrete example of how states could follow a NCSWC recommendation to implement this proposal by amending their workers' compensation laws. Section 47 of the New York Workers' Compensation Law currently provides that if an employee was employed in a process specifically listed in the schedule of diseases, and his disease is in the column directly opposite the description of the process, "the disease presumptively shall be deemed to have been due to the nature of that employment." 305 The New York's Workers' Compensation Law, and specifically Article 3 covering Occupational Diseases, could be amended, without removing the scheduled presumptions, by inserting a new subsection (b) to Section 47, adding an additional source of a presumption as envisioned by my proposal:

$\$$ 47(b). If the employee's disease is alleged to be the result of occupational exposure to a chemical or substance, other than those specifically listed in the schedule of processes and diseases found in Section 3, and the employee presents prima facie evidence that (1) the employee was exposed to the chemical or substance while in the employer's employment, and (2) the chemical or substance may cause the disease from which the employee suffers, then the disease presumptively shall be deemed to have been due to the nature of that employment. For purposes of this subsection, a prima facie showing that a chemical or substance may cause the disease from which the employee suffers may be established by evidence from one or more animal, epidemiological, or pharmacokinetic study conducted in accordance with established scientific principles, or by expert testimony grounded in the methods and procedures of science, relating to structural similarities of the chemical or substance to other chemicals or substances for which animal, epidemiological, or pharmacokinetic studies are available.

The presumption described in this subsection (b) shall not be available with respect to any chemical or substance for which there exists a Federal

Committee on Education and Labor on January 22, 2009, but no further action was taken. See Bill Summary \& Status: H.R. 365, Library of Congress, THOMAS, http://thomas.loc. gov/bss/101search.html (last visited Aug. 16, 2012) (Search Bill Summary \& Status for the 111 th Congress, H.R. 635).

304 The 1972 NCSWC recommendations were similarly backed by threat of federal workers' compensation legislation. See NAT'L ACAD. OF SOC. INS., supra note 302, at 15. The adoption of state workers' compensation statutes began before the U.S. Supreme Court had reinterpreted the commerce clause of the U.S. Constitution to permit broad federal regulation of private sector employees. See id. at 7. A threat of national legislation on occupational disease would be warranted in light of studies suggesting that the vast majority of costs from occupational disease are not compensated by existing state workers' compensation laws. See Leigh \& Robbins, supra note 21, at 709.

${ }^{305}$ N.Y. WORKERS' COMP. LAW § 47 (McKinney 2005); see also infra Appendix. 
Occupational Safety and Health Administration (OSHA) permanent Permissible Exposure Limit (PEL) standard. Except for the scheduled processes and diseases governed by Section 47(a) of this Chapter, where a Federal OSHA PEL standard exists the employee shall not be entitled to compensation under Article 3 of this Chapter unless the employee establishes either: (a) by a preponderance of the evidence, that the employee was exposed to the chemical or substance at levels exceeding the OSHA PEL; or (2) by clear and convincing evidence, that the employee's disease was caused by exposure to the chemical or substance, even though the employee was exposed at or below the PEL.

In order to include chemical manufacturers and suppliers in the ex post compensation scheme, Article 3 of New York's Workers' Compensation Law could be further amended to permit employers to include chemical manufacturers and suppliers as part of the apportionment scheme. Section 44 of the Workers' Compensation Law currently provides that the "total compensation due shall be recoverable from the employer who last employed the employee in the employment to the nature of which the disease was due and in which it was contracted," but further provides that such employer may seek "apportionment of such compensation among the several employers who since the contraction of such disease shall have employed such employee in the employment to the nature of which the disease was due." 306 This section could be amended to provide that employers may include in apportionment proceedings any chemical manufacturers or suppliers (which should be defined in the definitions section of the statute) that manufactured the chemical at issue or distributed the chemical at issue to the employer(s). The full amount of compensation due could be apportioned to any such chemical manufacturers or suppliers if the employer(s) can establish at a hearing that the entities supplied any amount of the chemical or substance at issue. Such entities could avoid apportionment if they can demonstrate at a hearing that the employer(s), in using the chemical or substance, failed to comply with the precautionary information provided by the manufacturer or supplier on the MSDS.

The statutory amendments required to implement my proposal will vary from state to state, and the details of particular proposals should be left to the state legislatures. The goal of the legislative amendments, however, should be effectively to implement the two key features of my proposed reform: a default burden allocation framework on the element of causation and the inclusion of chemical manufacturers and suppliers in the ex post compensation arrangements. 


\section{Remaining Challenges}

\section{Solving the Trade Secret Problem}

The assertion of trade secret protection is a potential threat to the efficacy of any worker disease regulatory system, including the one proposed herein. ${ }^{307} \mathrm{By}$ claiming that the diacetyl substitute compounds are trade secrets, food-flavoring manufacturers have prevented OSHA and NIOSH from effectively evaluating the chemicals to which microwave popcorn employees may be currently exposed. ${ }^{308}$ Any proposed regulatory solution must consider the difficulties raised by such intellectual property right claims.

Under the status quo regime, there is significant upside and little cost to the manufacturer in asserting a trade secret. Regardless of whether the claim is legitimate or whether the manufacturer actually has competitive concerns, an assertion of trade secret protection can be a roadblock to regulation, prevent the development of toxicity information that might suggest health hazards, and prevent workers from receiving both ex ante and ex post compensation for exposures to the substance.

A default burden allocation scheme, by contrast, may achieve a more efficient level of trade secret protection by placing the costs and benefits of revealing the information completely in the hands of the purported trade secret owners - those in the best position and with the best information to make such determinations. To illustrate, assume that a manufacturer is producing an artificial butter flavor using a diacetyl substitute, and that the manufacturer is considering whether to assert a trade secret protection over the proprietary chemical structure of the substitute. If the competitive value of the purported trade secret to the manufacturer is very high, and (knowing the chemical structure of the substitute) the manufacturer reasonably anticipates that exposures to the substitute are safe, even at high levels, then it will not produce detailed information about the chemical composition of the substitute in order to convince OSHA to enact a permanent PEL. Instead, it will keep information about the chemical composition confidential, expecting no or few claims of illness or disease from exposure to the substitute. If forced to defend a compensation claim under the default burden-shifting framework, it will do so by developing and presenting any available evidence on the toxicity or chemical structure of the substitute, and may be able to file such evidence under seal in order to preserve the competitive value of its formula.

If, however, the competitive value of the purported trade secret to the manufacturer is actually low (under the status quo, it might use the trade secret

307 See Lin, supra note 1, at 962 ("In addition, [government agencies and consumer organizations] may not be able to access the information needed to conduct safety testing because of trade secret claims by manufacturers."); McGarity \& Shapiro, supra note 257 , at 38 n.233; Wagner, Commons Ignorance, supra note 17, at 1699-1705.

308 See supra notes $103-08$ and accompanying text. 
claim primarily to avoid regulation rather than for competitive reasons) and the manufacturer reasonably believes that exposure to the substitute at high levels may be risky, but at low levels should be safe, then it will have an incentive under the default burden allocation scheme to develop and turn over toxicity information establishing that dose-response relationship. The secrecy of the chemical composition of the substitute will hold little value to the manufacturer, and not developing or divulging toxicity information will do the manufacturer no good because the burden of disproving causation will remain on the manufacturer unless it can convince OSHA to adopt a PEL for the compound.

In this way, the default burden allocation system forces chemical manufacturers to internalize and carefully weigh the costs and benefits of asserting trade secret protection over their newly developed chemical compounds. In contrast to the status quo, the default burden allocation system may encourage the divulgence or preservation of purported trade secrets at socially optimal levels.

\section{Biased Science}

A default burden allocation regime that includes chemical manufacturers in the ex post compensation system is more likely to generate new scientific information than the status quo and at least some of the recent regulatory proposals. One acknowledged limitation of this proposal, however, is that the source of the new science will be interested parties. As Professors Wagner and McGarity explain in Bending Science, interested parties have a strong economic incentive and multiple opportunities in the process of developing science to influence or, to borrow their term, "bend" the science in order to arrive at a desired outcome. ${ }^{309}$ One potential criticism of my proposal is that it may lead to more science, but it will just be more flawed science, brought to you by profitmotivated chemical manufacturers and self-interested employers.

This incentive, I posit, is inherent in the chemical exposure problem and can only be mitigated rather than eliminated. Chemical manufacturers, and, to a lesser, extent employers in industries using chemicals in their manufacturing process, are the entities in the best position to generate new science. OSHA does not have sufficient resources to develop significant amounts of new science on thousands of untested chemicals. The best it can do is to prioritize, in triage fashion, the deployment of its resources to studying and evaluating chemicals that are produced in high volumes or otherwise appear potentially risky based on their chemical structures and similarities to other compounds. Absent a funded super study, along the lines of Professor Lyndon's proposal, truly independent studies of thousands of chemicals appear to be out of reach. Government agencies, employees, unions, and worker advocate groups do not

${ }^{309}$ MCGARITY \& WAGNER, supra note 68 , at 3-5; see also MiCHAELS, supra note 51 , at 47 ("Follow the science wherever it leads? Not quite. This is science for hire, period, and it is extremely lucrative."). 
have sufficient resources to engage in such an extensive research undertaking. So we must rely on the least-cost information generators to pay for studies, and create the best possible circumstances for independent experts or worker groups to uncover any flaws in the science generated by the chemical industry.

This does not mean that a default burden allocation regime is doomed to fail under an avalanche of biased science. Reforms such as requiring disclosures of conflicts of interests for researchers, requiring the production of underlying data, requiring the production of studies reaching negative results, improving peer review, and improving regulatory analysis and oversight can mitigate the problems caused by incentives to bend science. ${ }^{310}$ My proposal can enhance these reform efforts. Under my proposal, OSHA will be able to redeploy some of its limited resources away from tasks like developing scientific information, coaxing employers into voluntary compliance arrangements, monitoring compliance with the Hazard Communication Standard, and defending its proposed standards against judicial attack and focus its resources more on the evaluation of newly available (but potentially bent) scientific data. Additionally, the public submission by industry of new toxicity studies to OSHA and NIOSH will allow advocates for worker safety and organized labor access to underlying data in order to scrutinize the results and challenge any industry-proposed OSHA PELs that are based on flawed science. While my proposed default burden-shifting system cannot solve the problem of biased science, it can help to mitigate it by improving the oversight and critical review of newly-generated science.

\section{CONCLUSION}

The free market and the current regulatory approaches to worker safety are failing to achieve efficient levels of risk and precaution and are also failing to adequately compensate workers for the expected costs of exposure to hazardous chemicals in the workplace. Exploring new, more creative regulatory approaches is justified and warranted.

In this paper, I have presented a novel regulatory proposal that takes advantage of the existing state workers' compensation systems and OSHA's existing regulatory framework. The proposal attempts to address the market failures caused by inadequate access to information and negative externalities imposed on third parties by employers and chemical manufacturers. The two key features of my proposal are: (1) a default burden allocation on the issue of causation that applies only in the absence of a permanent OSHA PEL standard, and (2) the inclusion of chemical manufacturers and suppliers in the workers' compensation system. Implementation of my proposal could be accomplished

310 MCGARITY \& WAGNER, supra note 68 , at 260-61 (describing ways in which government agencies can counteract advocates' attempts to bend science by recruiting respected, independent scientists to review submissions, penalizing abuses, and encouraging advocates with diverse interests to scrutinize submissions). 
by amendments to current state workers' compensation laws and could be coordinated by a new National Commission on State Workers' Compensation Laws.

Unlike other recent suggested reforms to worker disease laws, my proposal would both close the toxicity information gap and provide adequate compensation to workers for the expected costs of exposure to hazardous substances and chemicals. While opportunities will remain for chemical manufacturers and industry to influence the new science they produce, my proposal will permit OSHA regulators to direct their efforts to the evaluation of new science, rather than many of the less productive efforts they engage in under the status quo regime. By harnessing the financial incentives of the leastcost information providers, this proposal promises to solve the persistent problem of occupational disease caused by chemical exposures. 


\section{APPENDIX}

Table 1: New York Workers' Compensation Law

Section 3.2 Schedule of Occupational Diseases. Compensation shall be payable for disabilities sustained or death incurred by an employee resulting from the following occupational diseases:

\section{COLUMN ONE}

DESCRIPTION OF DISEASES

1. Anthrax.

2. Lead poisoning or its sequelae.

3. Zinc poisoning or its sequelae.

4. Mercury poisoning or its sequelae.

5. Phosphorus poisoning or its sequelae.

6. Arsenic poisoning or its sequelae.

7. Poisoning by wood alcohol.

\section{COLUMN TWO}

DESCRIPTION OF PROCESS

1. Handling of wool, hair, bristles, hides or skins.

2. Any process involving the use of or direct contact with lead or its preparations or compounds.

3. Any process involving the use of or direct contact with zinc or its preparations or compounds or alloys.

4. Any process involving the use of or direct contact with mercury or its preparations or compounds.

5. Any process involving the use of or direct contact with phosphorous or its preparations or compounds.

6. Any process involving the use of or direct contact with arsenic or its preparations or compounds.

7. Any process involving the use of wood alcohol or any preparation containing wood alcohol. 
[Continued from previous page]

\section{COLUMN ONE}

DESCRIPTION OF DISEASES

8. Poisoning by benzol or nitro-, hydro-, hydroxy-, and amido-derivatives of benzene (dimitrobenzol, anilin, and others), or its sequelae.

9. Poisoning by carbon bisulphide or its sequelae, or any sulphide.

10. Poisoning by nitrous fumes or its sequelae.

11. Poisoning by nickel carbonyl or its sequelae.

12. Dope poisoning (poisoning by tetrachlor-methane or any substance used as or in conjunction with a solvent for acetate of cellulose or nitro cellulose, or its sequelae[)].

13. Poisoning by formaldehyde and its preparations.

14. Chrome ulceration or its sequelae or chrome poisoning.

\section{COLUMN TWO}

DESCRIPTION OF PROCESS

8. Any process involving the use of or direct contact with benzol or nitro-, hydro-, hydroxyl-, or amidoderivatives of benzene or its preparations or compounds.

9. Any process involving the use of or direct contact with carbon bisulphide or its preparations or compounds, or any sulphide.

10. Any process in which nitrous fumes are evolved.

11. Any process in which nickel carbonyl is evolved.

12. Any process involving the use of or direct contact with any substance used as or in conjunction with a solvent for acetate of cellulose or nitro cellulose.

13. Any process involving the use of or direct contact with formaldehyde and its preparations.

14. Any process involving the use of or direct contact with chromic acid or bychromate of ammonium, potassium or sodium[,] or their preparations. 
[Continued from previous page]

\section{COLUMN ONE}

DESCRIPTION OF DISEASES

15. Epitheliomatous cancer or ulceration of the skin or of the corneal surface of the eye, due to tar, pitch, bitumen, mineral oil, or paraffin, or any compound, product or residue of any of these substances.

16. Glanders.

20. Radium poisoning or disability due to radioactive properties of substances or to Roentgen rays (X-rays) or exposure to ionizing radiation.

21. Methyl chloride poisoning.

\section{COLUMN TWO}

DESCRIPTION OF PROCESS

15. Handling or use of tar, pitch, bitumen, mineral oil, or paraffin or any compound, product or residue of any of these substances.

16. Care or handling of any equine animal or the carcass of any such animal.

17. Any process carried on in compressed air.

18. Any process involving mining.

19. Processes in the manufacture of glass involving exposure to the glare of molten glass.

20. Any process involving the use of or direct contact with radium or radioactive substance or the use of or direct exposure to Roentgen rays (X-rays) or ionizing radiation.

21. Any process involving the use of or direct contact with methyl chloride or its preparations or compounds. 
[Continued from previous page]

COLUMN ONE

DESCRIPTION OF DISEASES

22. Carbon monoxide poisoning.

23. Poisoning by sulphuric, hydrochloric, or hydrofluoric acid.

24. Respiratory, gastrointestinal, or physiological nerve and eye disorders due to contact with petroleum products and their fumes.

25. Disability arising from blisters or abrasions.

26. Disability arising from bursitis or synovitis.

27. Dermatitis (venenata).

28. Byssinosis.

\section{COLUMN TWO}

DESCRIPTION OF PROCESS

22. Any process involving direct exposure to carbon monoxide in buildings, sheds or enclosed places.

23. Any process involving the use of or direct contact with sulphuric, hydrochloric or hydrofluoric acids or their fumes.

24. Any process involving the use of or direct contact with petroleum or petroleum products and their fumes.

25. Any process involving continuous friction, rubbing or vibration causing blisters or abrasions.

26. Any process involving continuous rubbing, pressure or vibration of the parts affected.

27. Any process involving the use of or direct contact with acids, alkalies, acids, or oil, or with brick, cement, lime, concrete or mortar capable of causing dermatitis (venenata).

28. Any process involving exposure to raw cotton. 
[Continued from previous page]

\section{COLUMN ONE}

DESCRIPTION OF DISEASES

29. Silicosis or other dust diseases.

30. Any and all occupational diseases.

\section{COLUMN TWO}

DESCRIPTION OF PROCESS

29. Any process involving exposure to silica or other harmful dust.

30. Any and all employments enumerated in subdivision one of section three of this chapter. 
